\title{
LA BUENA FE CONTRACTUAL COMO NORMA JURÍDICA
}

\section{GOOD FAITH AS LEGAL NORM}

\author{
Adrián Schopf Olea*
}

\section{RESUMEN}

La buena fe contractual tiene la forma de una cláusula general cuya aplicación presupone delegar en el juez la tarea de definir en concreto los deberes de comportamiento o efectos jurídicos que se derivan de la misma y que constituyen el contenido implícito del contrato. Para realizar esa tarea el juez debe efectuar una valoración de todas las circunstancias concretas a la luz de los valores y fines remitidos por la buena fe, de manera que su aplicación presupone la existencia y ejercicio de una potestad delegada, pero estrictamente dirigida, orientada a concretizar el estándar del contratante leal y honesto. La necesidad del derecho de contratos de contar con un instrumento de esa naturaleza radica en la falta de exhaustividad de sus normas, permitiendo la buena fe, primero, morigerar la aplicación puramente formal de la ley cuando en atención a circunstancias particulares esa aplicación lleva a resultados insatisfactorios y, segundo, hacerse cargo de las transformaciones sociales que inciden en la institución del contrato y que resultan imprevisibles para el legislador. La buena fe permite, de esta manera, la aplicación coherente y el desarrollo interno del derecho de contratos, de un modo que resulta consistente con los valores $\mathrm{y}$ fines que lo fundan.

Palabras claves: Buena fe, contratos, cláusulas generales, conceptos jurídicos indeterminados, potestad delegada dirigida.

* Profesor de Derecho Civil, Universidad Adolfo Ibáñez y Universidad de Chile. Doctor en Derecho, Universidad de München. Dirección postal: Diagonal Las Torres 2640, Santiago. Correo electrónico: adrianschopf@uai.cl. Artículo recibido el 22 de mayo de 2018 y aceptado para su publicación el 7 de septiembre de 2018.

Este trabajo es parte del proyecto Fondecyt de iniciación n. ${ }^{\circ}$ 11160785, titulado "La buena fe contractual como potestad delegada dirigida". Agradezco especialmente a la señora Elke Halsen-Raffel, del Max-Planck-Institut für ausländisches und internationales Privatrecht, ubicado en la ciudad de Hamburgo, por su buena disposición y ayuda en el uso de la biblioteca y demás recursos bibliográficos durante una breve estancia de investigación en ese instituto, de la que obtuve un significativo provecho. 


\begin{abstract}
Good faith in Contract Law has the form of a general clause. Its application presupposes a delegation to the judge of a power to determine in particular cases the specific content of the legal duties or the legal effects implied in a contract. In order to carry this task forward, the judge must assess all the circumstances specific to the case in light of the values and purposes to which good faith points at. Its application, therefore, presupposes the exercise of a delegated but strictly directed power, aimed at specifying the meaning of the good faith standard. The need for such a standard stems from the lack of exhaustivity of the norms of Contract Law. Thus, good faith allows alleviating the unsatisfactory results brought forth by a formalistic application of the Law of Contract and also giving due consideration to the changes in economic and social circumstances which were unforeseeable to the legislator. In this sense, good faith fosters a coherent application and a development of Contract Law that is consistent with its foundational goals and values.
\end{abstract}

Keywords: Good faith, contracts, general clauses, undetermined legal concepts, directed power.

\title{
I. EL LUGAR DE LA BUENA FE EN EL DERECHO PRIVADO
}

La buena fe constituye un principio general del derecho privado, según una tendencia ampliamente extendida en el derecho nacional. En la doctrina se encuentra consolidada la idea que "la buena fe es un principio general del derecho" ${ }^{1}$, mientras que en la jurisprudencia se ha reconocido reiteradamente que la buena fe "tiene el carácter y naturaleza de principio general del derecho, que inspira todo nuestro ordenamiento jurídico"2.

${ }^{1}$ LÓPez y Elorriaga (2017), p. 428. Véase en igual sentido, entre otros, Fueyo (1990), p. 144 y ss.; Corral (2010), p. 68; Peñailillo (2003), p. 50; Boetsch (2011), p. 46; De la Maza (2014), pp. 201 y 213; SAavedra (1996), p. 360 y ss.

${ }^{2}$ Construcciones e Inversiones C. P. M. Limitada con Banco Santander Chile, (2010). Entre las innumerables sentencias que califican a la buena fe contractual como un principio general del derecho, pueden verse, entre otras, Luis Pérez Inostroza con Lucía Pérez Inostroza (2018); Inmobiliaria Velamar S.A.C. con Teresa Godoy Muñoz (2018); Transporte Travasa Limitada con HDI Seguros S.A. (2018); Servicio Nacional del Consumidor con Ticket Fácil S.A. (2018) ; Juan Salinas Sepúlveda con Servicio de Salud Atacama (2017); Macarena Bustos Valdés con María Lombardi Aranda (2016); Patricio Quezada Petersen con Gabriela Rivas Moraga (2016); Wilibaldo Moreno Loyola con Banco Santander Chile (2015); Castro Hidalgo Leonel con Araneda Campos Mauricio (2014); Administradora de Recursos Humanos y Marketing en Línea Apedex Limitada con Distribución y Servicio 
La tendencia es análoga en el derecho comparado. Si bien con un valor diferenciado, los más importantes ordenamientos jurídicos extranjeros tienden a coincidir en que la buena fe constituye un principio general del derecho privado ${ }^{3}$. En los ordenamientos jurídicos pertenecientes al derecho continental la buena fe tiene un reconocimiento generalizado, el que se expande a los más variados ámbitos. La mayoría de los sistemas legales codificados contienen en ese sentido una disposición legal que reconoce con alcance general el valor de la buena fe, mientras que muchas disposiciones más específicas son, a su vez, vistas como concreciones especiales de ese principio regulador de alcance más general ${ }^{4}$.

En el derecho chileno, la disposición legal que reconoce con carácter general el principio de la buena fe contractual es conocidamente el art. 1546 del Código Civil. Según esa disposición,

"los contratos deben ejecutarse de buena fe, y por consiguiente obligan no sólo a lo que en ellos se expresa, sino a todas las cosas que emanan precisamente de la naturaleza de la obligación, o que por la ley o la costumbre pertenecen a ella".

Si bien la señalada disposición se limita a reconocer valor a la buena fe en el ámbito del derecho de contratos, existe acuerdo en cuanto a que la misma consagra el principio de buena fe con un alcance más general, habiéndose sostenido a este respecto que la norma legal según la cual debe actuarse con arreglo a la buena fe "no debe limitarse al ejercicio de los derechos y al cumplimiento de las obligaciones surgidas de la fuente contractual", sino que, "esa norma tiene aplicación abierta y general, sin una necesaria limitación" .

De esa manera se sigue una tendencia generalizada en nuestra práctica jurídica, en cuya virtud diferentes normas jurídicas desarrolladas a propósito del derecho de contratos son expandidas a diversos ámbitos del derecho privado, cuestión que tiene su origen tanto en el predominio

D y S S.A. (2012); Luis Pérez Castro con Aguas Araucanía S.A. (2011) y Marcela Conejera Marchant con Jumbo Administradora S.A. (2010).

${ }^{3}$ Véase Whittaker y Zimmermann (2008), p. 8 y ss.; Stempel (2016), pp. 1 y 37 ss.; Grüneberg (2018), n. ${ }^{\circ}$ 1; Looschelders y Olzen (2015), n. ${ }^{\text {os }} .1160$ ss.; Díez-Picazo (2007), p. 59 y ss.; Carrasco (2017), n. ${ }^{\circ} 11 / 64$, p. 512; Miquel (1991), p. 37.

${ }^{4}$ Véase Hesselink (2011), p. 619, donde se contiene una referencia a las disposiciones legales que consagran el principio de buena fe en algunos de los más importantes códigos civiles europeos. Una referencia análoga, pero referida a los códigos civiles latinoamericanos, se encuentra en Eyzaguirre y Rodríguez (2013), pp. 141-142.

${ }^{5}$ Fueyo (1990), p. 158; en el mismo sentido, Corral (2010), p. 68; Peñailillo (2003), p. 51 . 
del contrato en nuestra tradición jurídica, como en el reconocimiento de que la relación contractual constituye la más paradigmática relación jurídica de derecho privado. Nada de extraño existe en ese sentido en el reconocimiento legal y desarrollo de la buena fe como principio general del derecho privado a propósito del derecho de contratos, desde donde ha expandido su ámbito de vigencia y aplicación a otras áreas del derecho de obligaciones y derecho privado en general ${ }^{6}$.

El reconocimiento generalizado de la buena fe en la doctrina, así como su reiterada invocación por los tribunales de justicia para fundamentar sus sentencias en la resolución de los más variados conflictos de relevancia jurídica, contrasta radicalmente con la falta de claridad que existe respecto de su preciso significado y alcance en cuanto norma jurídica. En particular, no resulta del todo claro cuál es exactamente el contenido sustantivo de la buena fe contractual, ni cuál es la forma jurídica que adopta, resultando, además, incierto cuáles son las potestades y los espacios de discreción judicial que su aplicación presupone en un caso particular. Los deberes de comportamiento y demás efectos jurídicos que se derivan de la buena fe en la configuración de la relación contractual son, de esta manera, en su gran mayoría indeterminados e inciertos. En razón de lo anterior, la definición del significado y alcance legal de la buena fe contractual se presenta como una de las más difíciles tareas con las que debe confrontarse la doctrina, configurándose la misma como un verdadero acertijo jurídico. Lo anterior resulta altamente problemático, esencialmente en razón de encontrarse en tensión con los postulados de la certeza jurídica y la calculabilidad de las decisiones judiciales, los que tienen una especial importancia en el ámbito del derecho de contratos, donde la seguridad jurídica constituye un presupuesto indispensable para la fluidez del tráfico y el normal desarrollo de las relaciones de intercambio y cooperación que constituyen el comercio, todas las cuales se canalizan a través de la figura del contrato. En la práctica legal, la que se encuentra con la necesidad de contar con normas precisas y de resolver los conflictos de relevancia jurídica entre privados hic et nunc, esas dificultades llevan a que la buena fe contractual sea usualmente identificada con los diferentes casos que constituyen aplicaciones y concreciones de la misma, de manera tal que se tiene por buena fe contractual aquello que los tribunales de justicia dicen usualmente y en concreto que es ${ }^{7}$. La señalada identificación de la buena fe contractual con sus diferentes aplicaciones y concreciones

${ }^{6}$ LÓPEz y Elorriaga (2017), pp. 428 y 429; Corral (2010), p. 69 y ss. y 90 y ss., sobre la extensión del ámbito de vigencia de la buena fe en el derecho chileno.

${ }^{7}$ Sobre la buena fe en la jurisprudencia, véase SAN MARTín (2015), p. 159 y ss. y CoRRAL (2010), p. 67 y ss. 
particulares puede tenerse, en principio, por correcta, con la reserva de que las mismas no se dan en un contexto de completa discreción judicial o desarrollo libre del derecho de contratos por los tribunales de justicia ${ }^{8}$.

En efecto, una revisión y análisis de las diferentes aplicaciones de la buena fe contractual en casos particulares da cuenta de que las mismas están en su gran mayoría dotadas de cierta uniformidad y se fundan en consideraciones homogéneas, de manera tal que todas esas aplicaciones tienen, en realidad, un pasado, un presente y un futuro común que las dota de continuidad ${ }^{9}$. Una vez asumida esa premisa, la tarea de la doctrina jurídica consiste en precisar el significado de la buena fe contractual, delineando de esa manera el marco jurídico en que se produce su aplicación por los tribunales de justicia y delimitando los espacios de discreción judicial asociados a la misma, de manera tal que resulte posible calificar fundadamente las diferentes concreciones judiciales de la buena fe contractual como una correcta o equivocada aplicación del derecho de contratos a una específica relación jurídica de derecho privado ${ }^{10}$. Ese es precisamente el objetivo de este texto, en el que se pretenden revisar los diferentes aspectos que configuran a la buena fe contractual como norma jurídica en el derecho de contratos. De acuerdo con ese objetivo, en lo que sigue se analiza el contenido sustantivo de la buena fe contractual, su forma jurídica y su particular modo de aplicación, para, finalmente, exponer las conclusiones de este trabajo.

\section{EL CONTENIDO SUSTANTIVO DE LA BUENA FE CONTRACTUAL}

\section{La buena fe como remisión al estándar del contratante leal y honesto}

En la doctrina tanto nacional como comprada la buena fe contractual es, en general, calificada como un concepto jurídico indeterminado, cuyo exacto contenido no se deja definir con precisión de una manera general y abstracta, que satisfaga condiciones necesarias y suficientes de aplicación ${ }^{11}$. De modo análogo a como sucede con todo concepto jurídico indeterminado, las dificultades asociadas a su precisión no significan, sin embargo, que la buena fe constituya una concepto jurídico vacío, carente de todo

\footnotetext{
${ }^{8}$ Véase Wieacker (1956), pp. 5-7; Bydlinsky (1990), p. 190 y ss.

${ }^{9}$ Cfr. Díez-Picazo (1986), p. 17.

${ }^{10}$ Véase Bydlinsky (1990), p. 194.

${ }^{11}$ Eyzaguirre y Rodríguez, (2013), p. 140 y ss.; Tapia (2015), p. 537; Ferreira (1984), pp. 105-106; Schubert (2016), n. ${ }^{\circ} 3$; Grundmann (2006), pp. 2-3.
} 
contenido semántico, que resulte compatible con cualquier tipo de consideración $^{12}$. La particularidad de todo concepto jurídico indeterminado como el de la buena fe contractual es, en realidad, que su aplicación no puede efectuarse de una manera meramente mecánica, sino que presupone siempre un acto de evaluación y valoración del juez en cada caso particular, efectuado sobre la base de un conjunto de directivas a que ese mismo concepto remite, y que lo dotan de un contenido relativamente preciso en un contexto concreto ${ }^{13}$. Los conceptos jurídicos indeterminados tienen, en este sentido, un significado jurídico relativamente preciso, en la medida que indican cuales son las directivas y consideraciones que resultan pertinentes en sus diferentes presupuestos de aplicación, permitiendo, de este modo, su concreción en cada caso y contexto particular ${ }^{14}$. De modo análogo a como sucede con los restantes conceptos jurídicos indeterminados, los casos particulares en que la buena fe es concretizada en un deber de conducta o efecto jurídico específico tienen la virtud de dotarla sucesivamente de un contenido delimitado, de manera tal que el respectivo marco jurídico y la suma de esos casos y contextos particulares resultan determinantes para los efectos de poner al descubierto su sentido $\mathrm{y}$ alcance ${ }^{15}$.

A la luz de ese trasfondo, la buena fe puede ser concebida como un 114 principio general del derecho privado, que remite a un conjunto de directivas que no han sido expresadas en el acuerdo contractual, relativas a la lealtad, honestidad y consideración recíproca que las partes contratantes pueden razonablemente esperar en su comportamiento mutuo, en atención a la especial relación que se ha formado entre ellas en virtud del contrato. El cumplimiento de ese conjunto de directivas presupone satisfacer un específico estándar de conducta, de manera tal que a través del establecimiento de la buena fe contractual como elemento constitutivo de la relación obligatoria, el derecho impone la observancia de un determinado estándar de comportamiento que debe ser cumplido por las partes contratantes durante todo el desarrollo de la relación contractual, desde su más básica gestación hasta su completa y total disolución. Ese estándar de conducta es el estándar del contratante leal y honesto, el que esencialmente implica honrar la confianza que supone la especial relación de intercambio y cooperación que subyace al contrato, de modo de no comportarse abusivamente y no defraudar las legítimas expectativas de

${ }^{12}$ Larenz (1991), p. 223; Heinrich (2000), pp. 317 y 392, ambos con referencia a TOPITSCH (1972), pp. 17 y 28.

${ }^{13}$ Wieacker (1956), pp. 13 y 19; STONe (1964), pp. 263-264, en general respecto de lo que denomina categorías jurídicas de referencia indeterminada.

${ }^{14}$ Cfr. Engisch (2010), p. 144.

${ }^{15}$ Whittaker y Zimmermann (2008), p. 31. 
comportamiento de la parte contraria, en atención a la finalidad económica o el propósito práctico que subyace a la convención ${ }^{16}$.

Los tribunales superiores de justicia chilenos han dado a la buena fe contractual un alcance general análogo al referido, resolviendo reiteradamente que esta invoca

"el modo sincero y razonable con que se procede, razón por la cual está íntimamente relacionada con la idea de rectitud, de intención y de lealtad",

exigiendo a los contratantes "el deber de comportarse correcta y lealmente en sus relaciones mutuas"; ${ }^{17}$ que

"es un estándar de conducta, que al darle contenido es empleado como sinónimo de probidad, lealtad, confianza, seguridad, honorabilidad"18

y que "se traduce en un comportamiento honesto, leal y veraz"19.

La principal particularidad del estándar del contratante leal y honesto al que remite la buena fe contractual es que este implica comportarse de un modo que no solo considera los propios intereses, sino que, también, los de la parte contraria, lo que en esencia supone morigerar el principio en cuya virtud a cada contratante corresponde cautelar sus propios intereses en los distintos momentos de la relación contractual ${ }^{20}$. El contrato es conocidamente el medio o instrumento que el derecho privado pone a disposición de las personas particulares para alcanzar sus propios fines, organizar sus intereses y, de esta manera, dar forma jurídica a sus relaciones recíprocas de intercambio y cooperación en el marco de una economía de mercado, caracterizada por la existencia de decisiones que son adoptadas

${ }^{16}$ Véase Whittaker y Zimmermann (2008) pp. 30-31; Larenz (1987), pp. 125-126; Looschelders y Olzen (2015), n. ${ }^{\text {os }} 140-142$; Grüneberg (2018), n. ${ }^{\circ}$. 6; Díez-Picazo (2007), p, 61.; Carrasco (2017), n. ${ }^{\circ}$ 11/57, p. 507; López y Elorriaga (2017), p. 435.

${ }^{17}$ Construcciones e Inversiones C. P. M. Limitada con Banco Santander Chile (2014).

${ }^{18}$ Administradora de Recursos Humanos y Marketing en Línea Ltda. con Distribución y Servicio D y S. S.A. (2012).

${ }^{19}$ Paola Flores Clunes y otros con Parque Arauco S.A., (2013). Véase. en un sentido similar, entre otras, Servicio Nacional del Consumidor con Ticket Fácil S.A. (2018); Patricio Quezada Petersen con Gabriela Rivas Moraga (2016); Víctor Mena Lobos con Banco Santander (2016); Servicio Nacional del Consumidor con Inmobiliaria Las Encinas de Peñalolén S.A. (2015); Frutícola El Aromo S.A. con María Consuelo Camposano Ibarra y otros (2014); Sociedad Constructora Miramar con Inversad Corza S.A.(2012).

${ }^{20}$ Looschelders (2014), n. ${ }^{o}$ 60, p. 27; Teichmann (1990), n. ${ }^{\circ} 4$. 
descentralizadamente por los diferentes agentes del mercado ${ }^{21}$. En su concepción más elemental, el contrato es concebido como un encuentro de intereses contrapuestos, en que cada parte atiende exclusivamente la realización de sus propios fines e intereses, sin ninguna consideración a los de la parte contraria ${ }^{22}$. De conformidad a esa doctrina individualista del contrato, que en el Common Law se expresa en la regla caveat emptor, a cada parte contratante corresponde cautelar sus propios fines e intereses tanto en la negociación como en la determinación del contenido y ejecución del acuerdo contractual. Si bien esa concepción constituye el presupuesto o punto de partida fundamental de la doctrina del contrato en el derecho contemporáneo, la misma es complementada por consideraciones que limitan las conductas que pueden tenerse por legítimas en la consecución de los propios fines e intereses, lo que supone que en un cierto punto las partes de un contrato deben considerar no solo sus propios intereses, sino que, también, los de la parte contraria en el desarrollo de la relación contractual, todo lo cual tiene su reconocimiento más generalizado en la buena fe contractual. En este sentido, la buena fe da cuenta que el contrato no solo supone una relación constituida sobre la base de un encuentro de intereses y fines divergentes, donde a cada parte corresponde cautelar sus propios intereses, sino que es, también, expresivo de una relación de cooperación, que en cierta medida supone considerar también los legítimos intereses de la parte contraria para los efectos de satisfacer la finalidad económica o el propósito práctico que subyace a la convención. La radical individualidad y autonomía expresada en el principio de la autonomía de la voluntad (Código Civil, art. 1545) es complementada en este sentido por la cooperación y la confianza expresadas en el principio de la buena fe contractual (Código Civil, art. 1546), constituyendo ambos postulados los pilares más esenciales sobre los cuales se construye la institución del contrato en el derecho contemporáneo, la cual solo se deja entender adecuadamente a partir de una doctrina que integre tanto el principio de la autonomía privada como el principio de la buena fe contractual. Mientras la autonomía privada se refiere a los aspectos explícitamente acordados por las partes contratantes, el estándar del contratante leal y honesto se refiere a lo que no se encuentra expresado en el acuerdo contractual, pero constituye un presupuesto indispensable de realización del mismo, de manera tal que través de la buena fe contractual el derecho cautela los legítimos intereses de las partes contratantes más allá de su explícito

${ }^{21}$ Flume (1979), p. 7 y ss. y 12 y ss.; KöHler (2017), § 8, n. ${ }^{\circ} 1$, p. 102; Morales (2006), p. 325 .

${ }^{22}$ Véase Kötz (2012), n. ${ }^{\text {os }} 22-25$, p. 11 y ss.; ZwEIgerT y Kötz (1996), p. 314 y ss.; Farnsworth (2004), § 1.2, § 1.7, p. 5 y ss. y 19 y ss.; Claro (1937), n. ${ }^{\circ} .681$, p. 9. 
reconocimiento en la promesa contractual. El contenido del contrato en cuanto ordenamiento privado que regula las relaciones recíprocas de las partes contratantes se compone de ambos aspectos: lo expresamente acordado por las partes en virtud de la autonomía privada y lo implícitamente presupuesto en el mismo en virtud de la buena fe contractual ${ }^{23}$.

\section{La confianza como bien jurídico cautelado por la buena fe}

El valor central que en último término subyace a la buena fe contractual en cuanto principio ordenador de la relación obligatoria es la confianza que implica la relación de intercambio y cooperación que subyace al contrato. No es de extrañar en ese sentido que el enorme desarrollo alcanzado en el último tiempo por la buena fe contractual, tanto en el derecho nacional como en el derecho comparado, tienda a coincidir con el creciente valor atribuido a la confianza en el desarrollo de relaciones económicas cada vez más complejas y sofisticadas que adoptan la forma de relaciones jurídicas de derecho privado ${ }^{24}$.

En términos generales, la existencia y conservación de un determinado grado de confianza constituye un presupuesto indispensable para la organización y configuración de toda especie de relaciones sociales, siendo también una condición necesaria para el desarrollo de todas las formas de intercambio, cooperación y organización en genera ${ }^{25}$. En particular, la configuración de todo modo de relación y organización social sobre la base de un determinado grado de confianza recíproca ha sido resaltada como una particularidad de la tradición jurídica occidental, lo que explica que la protección de la confianza tenga un valor constitutivo no solo para el derecho privado, sino que, también, para el derecho en general ${ }^{26}$. En ese sentido, tanto para el derecho privado como para el derecho público, la existencia de un acto que despierta cierto nivel de confianza y genera una legítima expectativa de comportamiento puede ser tenido por una razón suficiente para fundar una norma jurídica. Tanto la existencia del deber

${ }^{23}$ Véase Autr (2005), p. 10 y ss., sobre la tensión e incluso contradicción entre el individualismo y la protección del propio interés, por una parte, y la cooperación y consideración de los intereses del otro, por la otra, como valores que subyacen al derecho privado. De igual modo, véase también DE LA MAZA (2014), p. 202 y ss. y 206 y ss., con referencia a EisEnberg (2001), p. 240 y ss., respecto del derecho de contratos como un ordenamiento que se articula en torno al reconocimiento de valores e intereses divergentes.

${ }^{24}$ Barros (1983), p. 57.

${ }^{25}$ Larenz (1979), p. 80; Larenz (1987), p. 125.

${ }^{26}$ Schubert (2016), n. ${ }^{\circ} 11$; Looschelders y Olzen (2015), n. ${ }^{\circ} 143$, ambos con referencia a FIKENTSCHER (1975), pp. 109 y 179. 
de negociar honesta y lealmente las condiciones de un contrato ${ }^{27}$, como la existencia de la irrevocabilidad de un acto administrativo ${ }^{28}$, pueden ser explicadas de este modo por referencia a la confianza despertada por determinados actos con significación jurídica, sea que se trate de un acto de derecho privado, como en el primer caso, o uno de derecho público, como en el segundo. En ambas hipótesis, lo determinante para la justificación de la respectiva norma jurídica no es, sin embargo, la circunstancia de que alguien efectivamente haya confiado en los actos respectivos, sino que esos actos tengan el sentido y significado de despertar un determinado nivel de confianza y, de este modo, fundar una legítima expectativa respecto de un determinado comportamiento o una cierta situación de relevancia jurídica. Lo determinante, por lo mismo, es un juicio que primariamente atiende al sentido y efectos que objetivamente produce el acto que genera la confianza, y no al sujeto que confía en el mismo ${ }^{29}$.

En el ámbito general del derecho privado y, en especial, del derecho de contratos, la protección de la confianza no se agota en los intereses particulares y concretos de las partes contratantes, sino que tiene un valor constitutivo más general y abstracto, referido a la protección del tráfico jurídico en general, cuya materialización necesariamente presupone un determinado nivel de confianza entre los diferentes sujetos de derecho privado en sus respectivos tratos recíprocos ${ }^{30}$. El derecho de contratos, en cuanto instrumento dinámico de la economía que canaliza y permite la efectiva realización del comercio, presupone en este sentido un cierto nivel de confianza como condición indispensable de su materialización, cuya expresión más general en cuanto valor fundamental que subyace a la institución del contrato tienen precisamente lugar a través de la buena fe contractual ${ }^{31}$. En su significación más originaria y elemental la buena fe expresa la sujeción a la palabra empeñada, en cuanto sentirse vinculado por la propia declaración en razón de la confianza creada en la parte contraria, de manera tal que esta última puede tener la legítima expectativa de que la palabra empeñada será observada y la promesa contractual cumplida ${ }^{32}$. La existencia y protección de esa confianza constituye un presupuesto básico e indispensable para la realización de intercambios y el desarrollo del tráfico jurídico en general, sin la cual el comercio y gran parte de las relaciones económicas que se canalizan a

${ }^{27}$ Barros (2006), p. 1004 y ss.

${ }^{28}$ Maurer y Waldhoff (2017), n. o 22, pp. 325-326; González Pérez (2009), p. 69 y ss.

${ }^{29}$ Larenz (1979), p. 80.

${ }^{30}$ Bydlinski (1967), p. 131 y ss.

${ }^{31}$ LaRenz (1979), p. 80 y ss.

${ }^{32}$ Kaser y KnÜtel (2008) § 33, iv, n. ${ }^{\circ}$ 11, p. 179; Kunkel y Schermaier (2005), p. 96; Duve (2007), n. ${ }^{\text {os }} 4-7$, p. 280 y ss. 
través del contrato no resultan siquiera imaginables, de modo que junto a la autodeterminación individual en cuanto asunción voluntaria del deber contractual, la protección de la confianza y el tráfico jurídico pueden ser vistas como una razón adicional para fundamentar la obligatoriedad de la vinculación contractual ${ }^{33}$. La autonomía privada en cuanto potestad de las partes contratantes para configurar sus relaciones recíprocas de conformidad al acuerdo alcanzado tiene en este sentido un necesario correlato y presupuesto de ejercicio en la confianza depositada en la contraparte del contrato, de modo que cuando mediante la buena fe contractual se protege la confianza y seguridad del tráfico jurídico, se protege, también, de manera indirecta y en último término, la posibilidad de una efectiva realización de la autodeterminación individual ${ }^{34}$.

La circunstancia que el cumplimiento de la obligación contractual constituya la más básica expectativa de comportamiento de las partes contratantes tiene por consecuencia que la sola infracción del contrato constituya la más pura y elemental inobservancia a la buena fe contractual. La confianza expresada en la buena fe no se agota, sin embargo, en esa sola circunstancia, sino que comprende un conjunto o abanico mucho más amplio de expectativas implícitas respecto de lo que puede tenerse por el comportamiento exigible a las partes contratantes en sus tratos recíprocos con ocasión del desarrollo y ejecución del contrato. La relación obligatoria surgida del contrato está caracterizada por una especial vinculación entre las partes contratantes orientada al intercambio y la cooperación, lo que conlleva una intensificación de la confianza depositada en la parte contraria, la que está por sobre el solo cumplimiento de las obligaciones voluntariamente asumidas y los demás acuerdos expresamente alcanzados, de manera tal que a los contratantes resulta exigible comportarse en todo momento y bajo todas las circunstancias relativas al contrato como un contratante leal y honesto para los efectos de satisfacer la finalidad económica o propósito práctico que subyace a la convención. En términos generales, esa exigencia implica, entre otras cosas, que el contrato debe ser siempre interpretado y ejecutado según su sentido y finalidad por sobre su mero tenor literal; que más allá de las obligaciones explícitamente contraídas por los contratantes, estas tienen deberes u obligaciones conexas orientadas a realizar todo lo razonablemente exigible para cumplir con la finalidad económica o propósito práctico que subyace al contrato, debiendo, a su vez, abstenerse de realizar todo aquello que impida o ponga en peligro la efectiva realización de esa finalidad económica o propósito práctico; que los derechos y facultades fundados en la relación contractual deben ser

${ }^{33}$ Bydlinski (1967), p. 62 y ss.; Fried (2015), p. 7 y ss.

${ }^{34}$ Véase Heinrich (2000), p. 356; Bydlinski (1967), p. 63. 
siempre ejercidos de un modo leal y honesto que se condiga con su sentido y finalidad por sobre consideraciones puramente formales, de manera de evitar ejercicios abusivos, meramente oportunistas y por completo desconsiderados del interés de la parte contraria y que, en el extremo, la regla contractual puede ser, incluso, excepcionalmente corregida o modificada en atención a circunstancias por completo extraordinarias que atienden al efectivo cumplimiento de la finalidad económica o propósito práctico del contrato. No obstante sus diferencias específicas, todos esos efectos o consecuencias son siempre reconducibles a una legítima expectativa de comportamiento implícita respecto de la parte contraria, cuyo último fundamento se encuentra en la confianza que resulta inherente al contrato, y que es invocada como trasfondo de la buena fe contractual ${ }^{35}$.

La enorme flexibilidad de la institución contractual, así como su idoneidad para capturar diferentes tipos de relaciones de intercambio y cooperación, se muestra en que la particular naturaleza de la relación económica o social que subyace a una determinada especie de contrato puede tener una incidencia directa y determinante en la intensidad de la confianza depositada en la parte contraria, así como en las legítimas expectativas de conducta asociadas a la misma, lo que determina la diferente relevancia que la buena fe puede tener en la configuración de las distintas relaciones contractuales. Lo expresado da cuenta del diferente peso que puede tener la buena fe en cuanto principio ordenador de una determinada relación contractual, en función de la naturaleza económica o las particularidades del negocio que subyacen a la convención. En este sentido, es mayor la honestidad y lealtad que se pueden esperar de la otra parte en un contrato esencialmente orientado a la cooperación, como la sociedad, el joint venture o el mandato, que en uno preferentemente orientado al intercambio, como la compraventa, la prestación de servicios o el arrendamiento de bienes. De igual modo, es también mayor la lealtad y voluntad de cooperación que puede esperarse de la otra parte en un contrato que ha perdurado largamente, como puede ser el caso en algunas hipótesis de suministro o distribución, que en un contrato que se ha ejecutado instantáneamente y de una sola vez, como lo compraventa de un bien ordinario o la prestación de un servicio esporádico. El criterio más relevante, sin embargo, para determinar la relevancia de la buena fe, en cuanto principio ordenador de la relación contractual, puede ser ante todo visto en la posición relativa de las partes contratantes, siendo

${ }^{35}$ Sobre las diferentes funciones y efectos de la buena fe contractual, entre otros, véase Schubert (2016), n. ${ }^{o} 82$ y ss.; Looschelders (2014), n. ${ }^{\circ} 73$ y ss., p. 32 y ss.; Díez-Picazo (2007), p. 62 y ss.; Miquel (1991), p. 37 y ss.; Eyzaguirre y Rodríguez (2013), p. 184 y ss.; Boetsch (2011), p. 115 y ss. 
decisivo el nivel de asimetría que pueda existir entre las mismas, sea por su fuerza económica o su respectivo nivel de sofisticación y especialidad en un determinado ámbito de actividad, todo lo cual condiciona la efectiva posibilidad de negociación y protección de los propios intereses por cada uno de los contratantes. De esta manera, en contratos estandarizados celebrados con consumidores, donde existen posiciones fuertemente asimétricas de poder que no pueden ser razonablemente remontadas, existe una mayor confianza respecto de que el contenido de la convención no contiene condiciones sorpresivas o particularmente desfavorables para quien no ha podido revisar y discutir sus términos, que en contratos largamente negociados entre partes sofisticadas, donde cada contratante ha podido cautelar sus propios intereses y negociar cláusulas precisas en su beneficio, de manera tal que la confianza depositada en que la contraparte contractual ha atendido tanto a los propios intereses como a los ajenos es mínima, estando el contrato mucho más fuertemente gobernado por lo acordado por las partes contratantes en virtud del principio de libertad contractual, que por cualquier otra especie de consideración fundamentada en la buena de contractual ${ }^{36}$.

En definitiva, si bien a todo contrato resulta inherente un cierto grado de confianza, el que se refleja en un conjunto de expectativas de comportamiento implícitas que sobrepasan la promesa contractual expresamente convenida por la partes, resulta posible distinguir una serie de criterios específicos que permiten diferenciar y precisar la intensidad de la confianza que subyace a una determinada relación contractual. En todos los casos esa confianza, así como el conjunto de expectativas de comportamiento implícitas a que la misma da lugar, tienen siempre su reconocimiento y protección más general en el derecho privado a través de la buena fe contractual, en cuanto principio ordenador de la relación obligatoria surgida del acto convencional.

\section{LA FORMA JURÍDICA DE LA BUENA FE CONTRACTUAL}

\section{La buena fe contractual como cláusula general}

El art. 1546 del Código Civil, en cuanto disposición legal que recoge con alcance general la buena fe contractual, así como sus equivalentes en el derecho comparado, es usualmente calificado como una cláusula general. De esta manera, tanto la doctrina nacional como extranjera asumen, en

${ }^{36}$ Véase Barros (2006), pp. 1006 y 1025; Eyzaguirre y Rodríguez (2013), pp. 186188; Miller, (2010), p. 495 y ss. y 498 y ss.; Hartkamp (1995), p. 71. 
general, que esa es la forma jurídica que adopta la norma legal que consagra la buena fe contractual ${ }^{37}$.

La determinación de qué es exactamente lo que significa que una norma legal constituya una cláusula general es una cuestión altamente controvertida en la doctrina jurídica contemporánea, teniendo las cláusulas generales un estatus extraordinariamente difícil y poco claro en el derecho privado $^{38}$. Si bien resulta posible encontrar el término clausula generalis en el derecho romano, la discusión teórica acerca de la noción de cláusula general, así como los esfuerzos metodológicos orientados a la racionalización de su aplicación, son propios del derecho contemporáneo ${ }^{39}$. En particular desde principios del siglo xx resulta posible observar un creciente interés por la precisión y modo de aplicación de las cláusulas generales, lo que en gran medida tiene su origen en el reconocimiento de la necesidad de incorporar mayor flexibilidad en la aplicación y desarrollo jurisprudencial del derecho privado, cuestión que contrasta radicalmente con la pretensión de completitud de la ley y el escepticismo propio de la codificación hacia la función judicial, donde las cláusulas generales eran mayoritariamente vistas como fuente de inseguridad jurídica y arbitrariedad judicial, al abrir significativos espacios de discreción en la aplicación del derecho ${ }^{40}$. Las cláusulas generales constituyen en ese sentido una concesión o reconoci122 miento del legalismo jurídico a la necesidad de flexibilizar las facultades de los jueces en la aplicación y desenvolvimiento del derecho privado ${ }^{41}$.

La relevancia que las cláusulas generales han tenido en el desarrollo más reciente del derecho privado, así como el lugar central que, por lo mismo, han alcanzado en la gran mayoría de los ordenamientos jurídicos contemporáneos, ha llevado a que la discusión a su respecto haya alcanzado cada vez mayor atención y relevancia, al punto de sostenerse que muchos de los principales problemas que la aplicación del derecho privado plantea a la ciencia jurídica convergen en la discusión en torno a las cláusulas generales, cuestión que vale especialmente para la disposición legal que consagra la buena fe contractual ${ }^{42}$. Las principales preocupaciones doctrinarias en torno a las cláusulas generales se han concentrado en dos cuestiones por completo esenciales: en primer lugar, precisar

${ }^{37}$ De la Maza (2014), p. 201; Eyzaguirre y Rodríguez (2013), p. 147; Stempel (2016), p. 14 y ss.; Grundmann (2006), p. 1 y ss. y 7; GrÜneberg (2018), n. ${ }^{\circ}$ 2; LoOsChelders y Olzen (2015), n. ${ }^{\text {os }} 1$ y 110; MiQuel (1991), p. 37 y ss.

${ }^{38}$ Looschelders y Olzen (2015), n. ${ }^{\circ} 1$.

${ }^{39}$ Gartska (1976), p. 96 . Véase Digesto, 4,6,26, (2); 4,6,33(2) y 4,6,1,1 para referencias a la noción de clausula generalis en el derecho romano.

${ }^{40}$ Looschelders y Olzen (2015), $\mathrm{n}^{\text {os }} 2$ y 3.

${ }^{41}$ Wieacker (1967), p. 476.

${ }^{42}$ Bydlinsky (1990), p. 189. 
las particularidades que definen las cláusulas generales, lo que supone avanzar hacía una noción más precisa de cláusula general y, en segundo lugar, racionalizar su aplicación y los espacios de discreción judicial a ellas asociadas, lo que supone responder la pregunta metodológica sobre la particular forma de concreción de las cláusulas generales en el proceso de interpretación y aplicación del derecho privado ${ }^{43}$.

En lo relacionado con la noción misma de cláusula general, la formulación de normas legales que asumen esa forma jurídica puede ser ante todo vista y entendida como un específica técnica regulación del comportamiento caracterizada por situarse en el extremo contrario a una ordenación estrictamente casuística y fragmentada, cuya principal particularidad es regular un ámbito de actividad recurriendo a un catálogo detallado de normas jurídicas específicas que definen con un alto grado de detalle el supuesto de hecho que es condición de su aplicación, así como los específicos deberes de conducta y demás efectos jurídicos atribuidos a la efectiva realización del respectivo supuesto legal ${ }^{44}$. En el extremo contrario, las cláusulas generales se caracterizan por definir su propio ámbito de aplicación de un modo extraordinariamente amplio, y por fijar de un modo relativamente indeterminado los deberes de comportamiento y demás efectos jurídicos asociados a la realización de la respectiva hipótesis legal. Si bien el legislador puede recurrir exclusivamente a uno u otro modelo regulativo, la ordenación del comportamiento con referencia a cláusulas generales o a reglas jurídicas más detalladas no constituyen métodos excluyentes, sino que, por el contrario, se trata técnicas de regulación del comportamiento que se complementan entre sí. Una formulación relativamente común, en que es observable esa complementación, se expresa en la introducción y definición de una cláusula general, la que es posteriormente desarrollada por reglas jurídicas más precisas que no tienen pretensión de exhaustividad, resultando, además, fundamentales para una adecuada interpretación de la respectiva cláusula general, en la medida que pueden ser concebidas como una concreción de la misma efectuada por el propio legislador ${ }^{45}$.

Una vez asumido que las cláusulas generales son ante todo una técnica de regulación del comportamiento, a las mismas suelen atribuírseles ciertos elementos o rasgos distintivos, con lo que se pretende diferenciarlas de otras normas jurídicas. Las cláusulas generales son en ese sentido típicamente caracterizadas por su extraordinaria generalidad, su alto nivel de abstracción y por su significativo grado de indeterminación conceptual ${ }^{46}$.

${ }^{43}$ Véase Auer (2005), p. 126; Miquel (1997), p. 308; Bydlinsky (1990), p. 195.

${ }^{44}$ Engisch (2010), pp. 158 y 162; Gartska (1976), pp. 96-97; Werner (1966), p. 7.

${ }^{45}$ Engisch (2010), p. 161; Werner (1966), pp. 13-14.

${ }^{46}$ Véase Schmidt (2009), p. 16 y ss.; Autr (2005), p. 130; Ohly (2001), p. 5 y ss.; 
Esa sola caracterización parece resultar, sin embargo, insuficiente, ya que tanto la generalidad, la abstracción y la indeterminación conceptual son, en realidad, características comunes que pueden atribuirse a la mayoría de las normas jurídicas que tiene su fuente en la ley. Todas las particularidades que suelen atribuirse a las cláusulas generales como rasgos distintivos de las mismas son de esta manera comunes a todas las normas legales, de modo que una diferenciación sobre la sola base de esos criterios resulta insuficiente ${ }^{47}$. Atendidas esas dificultades, el mayor grado de generalidad, abstracción e indeterminación conceptual de las cláusulas generales solo puede ser calificado como una particularidad que resulta posible concebir en relación con otras normas jurídicas, a su vez, caracterizadas por su mayor especialidad, grado de concreción y determinación conceptual, lo que supone un reconocimiento de que la diferenciación referida es esencialmente gradual ${ }^{48}$. La calificación de una norma jurídica como cláusula general solo es de esta manera posible en el contexto o por referencia a una serie de reglas jurídicas constituidas de una manera más detallada o acotada, respecto de las cuáles la primera es elevada a un escalón superior, precisamente en razón de su mayor grado de generalidad, abstracción e indeterminación conceptual ${ }^{49}$. En este orden de ideas, en relación con las demás normas legales que fijan los derechos, obligaciones y, en general, el 124 contenido de los diferentes contratos, la disposición legal que consagra la buena fe contractual puede ser vista como una cláusula general, al resultar más general, abstracta e indeterminada conceptualmente que cada una de esas normas jurídicas particulares, muchas de las cuales pueden ser, a su vez, vistas como concreciones legales del estándar del contratante leal y honesto ${ }^{50}$.

Si bien la caracterización de las cláusulas generales en atención a las particularidades señaladas contribuyen a su definición, esas solas consideraciones resultan insuficientes para dar cuenta de su particular constitución. Aunque puede ser tenido por correcto que las cláusulas generales tienen un mayor grado de generalidad, abstracción e indeterminación conceptual que otras normas jurídicas, su verdadero rasgo distintivo puede ser visto esencialmente en que, a diferencia de la mayoría de las normas legales que configuran el derecho privado, las cláusulas generales no establecen con precisión los deberes de comportamiento y demás efectos jurídicos específicamente ordenados para cada una de las hipótesis de hecho

HeinRich (2000), pp. 316-317; SCHMidt (1990), p. 235; Bydlinsky (1990) p. 195; Gartska (1976), p. 115.

${ }^{47}$ Véase Auer (2005), p. 131.

${ }^{48}$ Bydlinsky (1990), p. 195; Schmidt (2009), p. 18; Röthel (2004), pp. 33-34.

${ }^{49}$ Gartska (1976), pp. 114-115; Heinrich (2000) pp. 316-317; Auer (2005), pp. 131-132.

${ }^{50}$ Véase Schmidt (1990), p. 234. 
comprendidas en su ámbito de aplicación, sino que, en su lugar, regulan el comportamiento por referencia a un estándar o modelo de conducta que solo indica las directivas de comportamiento que deben ser observadas en las innumerables hipótesis de hecho comprendidas en el ámbito de aplicación de la norma, el que, según ya se señaló, es definido de una manera extraordinariamente amplia. El deber de conducta que debe ser observado en cada una de las innumerables hipótesis de hecho cubiertas por el ámbito de aplicación de la cláusula general no se encuentra de esta manera especificado con precisión en la propia norma jurídica, sino que tiene que ser derivado de la misma a partir del respectivo estándar o modelo de conducta que forma parte de la cláusula general, lo que supone atender, por una parte, al conjunto de directivas y guías de conducta que dotan el referido estándar de conducta de contenido y, por la otra, a todas las circunstancias y particularidades de hecho que configuran el caso concreto. La así denominada concreción de la cláusula general implica de esta manera derivar de la misma un deber de conducta o efecto jurídico específico que regule la particular relación de derecho privado, llenando de este modo el espacio en la ley dejado abierto por el legislador al regular el comportamiento por medio de una cláusula general ${ }^{51}$.

En el orden de ideas señalado, el art. 1546 del Código Civil, al disponer genéricamente el deber de las partes de actuar de buena fe, no establece cuál es la específica conducta que deben observar los contratantes en las múltiples hipótesis de hecho cubiertas por su ámbito de aplicación, limitándose por el contrario a establecer directivas o guías generales de conducta, en cuya virtud las partes de un contrato tienen el deber genérico de comportarse de acuerdo con el modelo o estándar de conducta del contratante leal y honesto durante todo el desarrollo y en todos los momentos de la relación contractual, lo que en esencia implica no comportarse abusivamente y no defraudar las legítimas expectativas de comportamiento de la parte contraria, considerando en un cierto punto no solo los propios intereses, sino que, también, los de la parte contraria, en atención a la finalidad económica y el sentido práctico de la específica relación contractual. La determinación de qué es lo que eso exactamente significa y cuáles son los específicos deberes de comportamiento y demás efectos jurídicos que de ello se siguen, es algo que necesariamente queda abierto y tiene que ser precisado en una fase o estadio posterior, sobre la base de hechos y circunstancias más precisas y acotadas, a la luz de las directivas y guías a las que remite el estándar del contratante leal y honesto, cuestión que supone, a su vez, atender a los valores y fines que subyacen a la institución del contrato. Si bien esa determinación puede ser efectuada tanto por

${ }^{51}$ Hedemann (1933), p. 58. 
el propio legislador como por los usos normativos, según se deduce de manera inequívoca del tenor literal del art. 1546 del Código Civil, se trata de una tarea judicial por excelencia, en atención a la enorme cantidad de hechos y circunstancias concretas que pueden incidir relevantemente en la relación contractual.

La cuestión se plantea en términos análogos en el ámbito de la responsabilidad civil extracontractual, con ocasión de la aplicación de los arts. 2314 y 2329 inc. $1^{\circ}$ del Código Civil, que consagran la más típica e indiscutida de las situaciones en las que el legislador regula el comportamiento por medio de una cláusula general. De acuerdo con esa disposición legal, la responsabilidad civil extracontractual solo puede configurarse bajo la condición de un comportamiento doloso o culpable, siendo la culpa o imprudencia el elemento decisivo en la configuración de la responsabilidad civil, en la medida que esta es esencialmente un derecho de accidentes ${ }^{52}$. La culpa extracontractual presupone, a su vez, la infracción de un deber de comportamiento, remitiendo para los efectos de la determinación de ese deber al modelo o estándar de conducta del buen padre de familia, caracterizado por emplear el cuidado ordinario en la conducta susceptible de causar daños a otros en las interacciones espontáneas y no programadas entre particulares (Código Civil, art. 44 inc. $\left.1263^{\mathrm{o}} \mathrm{y} 4^{\mathrm{o}}\right)$. La norma no define cuál es ese cuidado ordinario y cuáles son los específicos deberes de comportamiento que deben ser observados en las múltiples e innumerables hipótesis de hechos cubiertas por su ámbito de aplicación, limitándose por el contrario a señalar que en todas esas hipótesis debemos comportarnos de conformidad al estándar del buen padre de familia. La definición de los específicos deberes de conducta que deben ser observados en cada caso tienen necesariamente que derivarse del referido estándar o modelo de conducta, cuestión que solo puede efectuarse a partir de hechos más precisos y por referencia a las directivas de comportamiento a las que remite el estándar o modelo de conducta del buen padre de familia que subyace a la culpa, cuestión que supone considerar tanto los valores como los fines que subyacen a la institución de la responsabilidad civil extracontractual. Esos valores y fines pueden ser identificados con la necesidad de protección de determinados bienes en intereses, por una parte, y necesidad de conservación de una amplia libertad de acción, por la otra ${ }^{53}$. La definición precisa de los deberes de comportamiento cuya infracción constituye la culpa pude ser efectuada por el legislador o los usos normativos en el evento de supuestos más

${ }^{52}$ Barros (2006), p. 75.

${ }^{53}$ Schopf (2015), p. 922; Looschelders (2012), n. ${ }^{\circ}$ 1168, p. 396; Larenz y Canaris (1994), p. 350. 
acotados, tratándose, sin embargo, de una típica tarea judicial, en atención a la enorme e inconmensurable cantidad de conductas en que unos pueden lesionar o afectar los bienes e intereses de otros ocasionándoles un daño o perjuicio ${ }^{54}$.

El art. 1546, por una parte, y los arts. 2314 y 2329 inc. $1^{\circ}$, por la otra, según se puede observar, tienen, de esta manera, la misma forma jurídica, diferenciándose esencialmente por su presupuesto de aplicación y por el contenido de los estándares o modelos de conducta que los integran, los que remiten a diferentes directivas de conducta, cuestión que, a su vez, está condicionada por los distintos valores y fines del contrato y la responsabilidad civil extracontractual en cuanto instituciones fundamentales del derecho privado ${ }^{55}$.

En definitiva, una vez asumido que las cláusulas generales implican una técnica de regulación del comportamiento, su verdadero rasgo distintivo puede ser visto en que, por una parte, definen su supuesto de aplicación de un modo extraordinariamente amplio y, por la otra, no establecen deberes de comportamiento o efectos jurídicos precisamente definidos, sino que incorporan un concepto jurídico indeterminado -buena fe, culpa- que remite a un estándar o modelo de conducta, cuyo contenido se compone de determinadas directivas de conducta, las que se vinculan con los valores y fines que subyacen a la respetiva institución de derecho privado y del que se derivan los deberes de comportamiento o demás efectos jurídicos específicos que deben ser observados en cada caso particular regulado por la respectiva cláusula general. En el orden de ideas señalado, el art. 1546 del Código Civil, en cuanto disposición legal que consagra la buena fe contractual, contiene una fundamental cláusula general de derecho privado, probablemente la más relevante en el ámbito del derecho de contratos, solo equiparable en importancia y centralidad a los arts. 2314 y 2329 inc. $1^{\circ}$ del Código Civil, que establecen la cláusula general más relevante en la configuración del derecho de la responsabilidad civil extracontractual. La cláusula general desarrollada sobre la base del art. 1546 tiene un ámbito de aplicación que se extiende a todos los momentos de la relación contractual y, más aún, a todos los momentos de toda relación jurídica de derecho privado caracterizada por una especial vinculación entre las partes, en cuya virtud estas deben en todo momento de la referida relación actuar de buena fe, esto es, comportarse según el estándar o modelo del contratante leal y honesto, lo que solo expresa un conjunto de directivas generales de comportamiento, sin indicar la conducta específica que, en

${ }^{54}$ Barros (2006), p. 80 y ss. y 97.

${ }^{55}$ Véase $\mathrm{S}$ CHOPF (2017), p. 69 y ss., sobre las diferentes funciones del contrato y la responsabilidad civil extracontractual en el derecho privado. 
concreto, es exigida a cada parte frente a determinadas circunstancias de la relación obligatoria, todo lo cual solo puede ser precisado en una fase o estadio posterior, sobre la base de hechos más precisos y acotados, a la luz de las directivas, valores y fines a los que remite la buena fe contractual ${ }^{56}$.

\section{Beneficios y riesgos de ordenar el comportamiento mediante la cláusula general del art. 1546 del Código Civil}

La gran ventaja de ordenar la relación contractual con una norma jurídica que asume la forma de una cláusula general como la contenida en el art. 1546 del Código Civil, es su enorme plasticidad y flexibilidad, la que le permite hacerse adecuadamente cargo de todas las circunstancias y particularidades que pueden afectar a la relación obligatoria surgida del contrato. La señalada plasticidad no solo permite aplicar el derecho de un modo que sea consistente con el sentido económico y la finalidad práctica del contrato cuando una aplicación puramente formal de la ley puede llevar a un resultado insatisfactorio, sino que tiene, también, una especial aptitud para resolver nuevos supuestos de hecho no explícitamente previstos por normas legales más precisas, presuponiendo la introducción de una cláusulas general, por lo mismo, un explícito reconocimiento a 128 la incapacidad del legislador de prever todos los hechos y circunstancias futuras que pueden resultar jurídicamente relevantes para la configuración de la relación contractual ${ }^{57}$.

La regulación del comportamiento mediante una cláusula general constituye en ese sentido un reconocimiento a la imposibilidad del legislador de prever todas las circunstancias y el desarrollo de todos los acontecimientos que configuran el futuro y que resultan relevantes para el contrato, de manera tal que la existencia de la buena fe contractual se funda, en último término, en la falta de exhaustividad de las restantes normas legales que conforman la institución del contrato. Una vez presupuesta esa premisa, la buena fe permite al derecho de contratos hacerse cargo de todas las particularidades de una específica relación contractual y ordenar los nuevos problemas legales producidos por los cambios y transformaciones tecnológicas, económicas y sociales que resultan relevantes para el desarrollo de las relaciones de intercambios y cooperación que tienen lugar al interior de los mercados, permitiendo de este modo, tanto la adecuada aplicación como el desarrollo del derecho de contratos, de una

${ }^{56}$ Véase LARENZ (1987), pp. 125-126.

${ }^{57}$ Véase Bydlinsky (2011), p. 582 y ss.; LoOschelders y Roth (1996), p. 198; WIEACKeR (1967), p. 476. 
manera que resulta consistente con los valores y fines que lo sustentan ${ }^{58}$. Es precisamente por eso que la buena fe tiene una función esencial no solo en la ordenación de la relación contractual considerando todas sus particularidades, sino que, también, en el desarrollo y desenvolvimiento del derecho de contratos a la luz de los constantes cambios económicos $\mathrm{y}$ transformaciones sociales que resultan relevantes para el mismo ${ }^{59}$. En el orden de ideas señalado, no es casualidad que algunos de los más importantes desarrollos recientes del derecho de obligaciones, que han tenido lugar tanto en el derecho nacional como en el derecho comparado, se hayan fundamentado en la buena fe contractual. Es el caso de figuras legales tan disímiles y relevantes como la responsabilidad precontractual, algunas de las hipótesis más relevantes de abuso del derecho, la teoría de la imprevisión y el control de cláusulas abusivas en condiciones generales de contratación y contratos con consumidores, entre otras ${ }^{60}$.

En no pocos casos, luego de un proceso de discernimiento práctico y de experiencia que lleva a la consolidación de la regla jurídica más adecuada, muchos de esos desarrollos jurisprudenciales y doctrinarios han sido posteriormente incorporados al ordenamiento jurídico mediante leyes específicas, dando cuenta de un especial modo de interacción entre legislación, judicatura y doctrina en la configuración del derecho priva$\mathrm{do}^{61}$.

La plasticidad y flexibilidad que la buena fe contractual introduce en el derecho de contratos es de esta manera su principal virtud, al dotarlo de una especial adaptabilidad, movilidad y dinamismo, permitiendo que la institución contractual efectivamente cumpla su función más esencial, en cuanto instrumento que permite la realización del comercio en el marco de una economía de mercado, permanentemente expuesta a ser afectada por cambios y transformaciones.

El gran riesgo de la buena fe contractual y, en realidad, de toda cláusula general, es visto la mayoría de las veces en la misma plasticidad y flexibilidad a la que debe todas sus virtudes. La amplitud de su presupuesto de aplicación y -sobre todo- la indeterminación de los deberes de conducta y demás efectos jurídicos ordenados por la buena fe contractual, es considerada una potencial fuente de inseguridad jurídica, arbitrariedad judicial y desformalización del derecho, en la medida que son esencialmente los jueces los encargados de definir los deberes de conducta y demás efectos

${ }^{58}$ Schubert (2016), n. ${ }^{\circ}$ 24; Looschelders (2014), n. ${ }^{\circ}$ 61, p. 23; Esser y Schmidt (1995), § 10 III, pp. 170-171.

${ }^{59}$ Véase Schmidt (2009), pp. 19-20; Bydlinsky (1990), p. 215; Beater (1994), p. 83 y ss.; MaYer-Maly (1981), p. 803 y ss.

${ }^{60}$ Schubert (2016), n. ${ }^{\circ} 24$.

${ }^{61}$ Véase Whittaker y Zimmerman (2008), pp. 31-32; Stempel (2016), pp. 23-24. 
jurídicos específicos ordenados por el estándar del contratante leal y honesto $^{62}$.

La buena fe contractual abre, de esta manera, un cierto espacio para que los jueces puedan hacer prevalecer sus propias convicciones subjetivas o ciertas tendencias valorativas por sobre lo ordenado por el legislador, con todos los riesgos que ello necesariamente conlleva ${ }^{63}$. La marginación o, a lo menos, minimización de esos riesgos, es la ventaja atribuida a una regulación más casuística, compuesta por un conjunto de reglas legales que con un alto grado de detalle precisan un determinado supuesto de hecho y le atribuyen deberes de conducta definidos con exactitud, determinando también con toda claridad los efectos jurídicos que se siguen de su inobservancia. A pesar de su mayor rigidez y su carácter mucho más fragmentario, la ventaja de un derecho de contratos altamente formalizado y construido sobre la base de un conjunto de reglas de esa especie, radica tanto en la certeza jurídica que otorgan las normas jurídicas que lo componen como en el reducido espacio que dejan a la discreción de los jueces en la aplicación del derecho privado, excluyendo, de esta manera, los riesgos de arbitrariedad judicial y vulgarismo jurídico. No obstante las ventajas señaladas, la aplicación estricta y puramente formal de un derecho de contratos así concebido puede resultar muchas veces contrario a los valores y fines que sustentan la institución contractual en algunas circunstancias concretas, al no resultar lo suficientemente abierto a la diferenciación y a las particularidades de una específica relación contractual, no teniendo además la aptitud para resolver nuevos conflictos jurídicos surgidos de las transformaciones económicas y sociales que puede afectar la relación contractual y que no han podido ser previstas por el legislador. Por lo mismo, un derecho de contratos así concebido no puede cumplir adecuadamente su función, pudiendo llegar a entrabar la fluidez del tráfico jurídico y el normal desarrollo de las relaciones de intercambio y cooperación que configuran el comercio. Esa es la razón que explica que, una vez alcanzado un determinado estadio de desarrollo del derecho de contratos, la aplicación estricta y puramente formal de sus normas jurídicas deba necesariamente ser complementada por alguna especie de cláusula general u otro instrumento jurídico equivalente, que resulte lo suficientemente flexible para juzgar las circunstancias especiales y los hechos nuevos que inciden relevantemente en la configuración de

${ }^{62}$ Véase Esser y Schmidt (1995), § 10 III, p. 170; Díez-Picazo (2007), p. 65; MiQuel (1991), p. 38 y, especialmente, Hedemann (1933), p. 66 y ss.

${ }^{63}$ Wieacker (1967), p. 477; Miquel (1997), p. 297 y ss. Véase en especial Rüthers (2012), p. 210 y ss. y 224 y ss., respecto de la función que las cláusulas generales y la buena fe pueden tener en una reinterpretación peligrosamente transformadora del derecho civil, precisamente en razón de su plasticidad y flexibilidad. 
la relación contractual, a la luz de los valores y fines que fundan la institución del contrato ${ }^{64}$. En ningún evento ello supone la sustitución de un conjunto de reglas legales más precisas por una ordenación jurídica del contrato a partir de una cláusula general estructurada en torno al principio de la buena fe contractual, tratándose más bien de una complementación.

En ese sentido, una vez superado el legalismo jurídico, su pretensión de completitud de la ley, y el escepticismo hacia la actividad judicial propio de la codificación, en la práctica del derecho privado contemporáneo, la oposición entre un conjunto de reglas que regulan con detalle el contenido de la relación contractual, por una parte, y la ordenación de ese mismo contenido sobre la base de una cláusula general que recurre a un estándar o modelo general de conducta abstracto e indeterminado como la buena fe contractual, por la otra, es resuelta a favor de un derecho de contratos que incorpora ambos tipos de normas jurídicas. El espacio dejado abierto por el legislador en el marco de reglas legales más detalladas, pero necesariamente insuficientes e inexhaustivas, pasa a ser cubierto de esta manera por una cláusula general como la que implica la buena fe contractual, para, de ese modo, dotar de flexibilidad y dinamismo el derecho de contratos, haciéndolo sensible a los diferentes contextos y a las constantes transformaciones sociales y económicas que resultan relevantes para el desarrollo del comercio y, en consecuencia, para los contratos. Esa estructura y diseño legal presupone, sin embargo, tanto un especial refinamiento de la jurisprudencia en el proceso de aplicación y concreción de la buena fe contractual como un freno y control crítico de ese proceso por la doctrina jurídica, como único modo de evitar una completa desformalización del derecho de contratos y su reemplazo por una justicia de mera equidad, cuyo fundamento no resulta posible encontrar en ningún otro lugar y que no tiene ningún otro límite que la sola conciencia y cabeza del juez de la causa ${ }^{65}$.

El señalado freno y control se produce, por una parte, delineando el contenido y forma jurídica de la buena fe contractual y, por la otra, precisando todas las particularidades que caracterizan su proceso de aplicación en un contexto particular.

\footnotetext{
${ }^{64}$ SCHERMAier (2000), p. 63.

${ }^{65}$ Véase Duve (2007), n. ${ }^{\circ}$ 18, p. 290.
} 


\section{LA APLICACIÓN DE LA BUENA FE CONTRACTUAL}

\section{La vinculación del juez a la ley en la aplicación de la buena fe contractual}

La buena fe constituye una norma jurídica positiva que forma parte del ordenamiento de derecho privado, que en razón de su contenido y particular forma jurídica no se deja aplicar mecánicamente mediante un simple juicio lógico o de subsunción, diseñado a partir de un entendimiento del derecho privado como un conjunto de reglas que definen con precisión el supuesto de hecho que es condición de su aplicación, así como las específicas consecuencias jurídicas atribuidas a la realización de la respectiva hipótesis legal ${ }^{66}$. En consideración a la innumerable variedad, complejidad e imprevisibilidad de los hechos que pueden resultar relevantes para las relaciones jurídicas entre personas particulares, la aplicación del derecho privado no se limita prácticamente nunca a una figura lógica acabada y claramente delimitada que permita un juicio mecánico de subsunción, de manera tal que lo dicho puede ser, en realidad, tenido por válido respecto de la gran mayoría de las normas jurídicas que conforman el ordenamiento jurídico de derecho privado ${ }^{67}$.

132 El distanciamiento del ideal constituido por el juicio lógico de subsunción o de una aplicación meramente mecánica del derecho por los tribunales de justicia se muestra, sin embargo, con especial radicalidad en la concreción de la buena fe contractual, la que siempre presupone un especial acto de valoración y de evaluación por parte del juez, orientado precisamente a concretizar y determinar los específicos deberes de conducta y demás efectos jurídicos que se siguen de la aplicación del estándar del contratante leal y honesto a una especifica relación contractual. A diferencia de otras normas legales que regulan el contenido de los contratos, la buena fe no indica los deberes de conducta específicos que las partes tienen la necesidad de observar, ni los otros efectos jurídicos que se pueden seguir de su aplicación, de modo que es el juez quien debe previamente precisar cuáles son esos deberes y demás efectos jurídicos, una vez verificados ciertos hechos y circunstancias particulares que resultan jurídicamente relevantes para la configuración de la relación contractual ${ }^{68}$. Solo una vez efectuado lo anterior puede determinarse si esos deberes de conducta han sido o no cumplidos por las partes contratantes, y cuáles

${ }^{66}$ Grüneberg (2018), n. ${ }^{\circ}$ 2; Schubert (2016), n. ${ }^{\circ}$ 2.; Looschelders y Olzen (2015), n. ${ }^{\circ}$ 113; Grundmann (2006), p. 3; Wieacker (1967), p. 477; Stone (1964), p. 263.

${ }^{67}$ Véase Wieacker (1956), p. 14; Larenz (1991), pp. 453-454; Bydlinsky (1990), p. 197.

${ }^{68}$ Véase Grundmann (2006), p. 3. 
son los efectos jurídicos que se siguen de su eventual inobservancia. Esa circunstancia, esto es, que sea el juez quien tenga que previamente definir y precisar el contenido de los específicos deberes de conducta y demás efectos jurídicos que se siguen de la aplicación del estándar del contratante leal y honesto, es lo que distancia de manera tan significativa la aplicación de la buena fe contractual del ideal del juicio lógico de subsunción, siendo, además, la diferencia respecto de la gran mayoría de las restantes normas legales, en que es el propio legislador quien establece con relativo detalle el contenido de los respectivos deberes de conducta o efectos jurídicos ordenados para una específica hipótesis legal. En razón de esa significativa indeterminación y los espacios de discreción que ello implica, la principal dificultad que presupone la aplicación de la buena fe contractual a un caso particular se refiere a la sujeción del juez a la ley, habiéndose llegado a sostener que la buena fe contractual no supone en realidad vinculación alguna para los tribunales de justicia, encubriendo en verdad la creación judicial libre de normas jurídicas en el marco del derecho de contratos ${ }^{69}$. La relación entre legislación y judicatura es de esta manera el problema más básico y fundamental que la aplicación de la buena fe contractual plantea en el derecho de contratos ${ }^{70}$.

Aunque parezca una obviedad, resulta necesario recalcar que la premisa fundamental en la aplicación de la buena fe contractual a una determinada relación obligatoria solo puede ser la esencial vinculación del juez a la ley. La buena fe contractual es una cláusula general que forma parte del conjunto de normas jurídicas que conforman el derecho de contratos, de manera tal que se trata de una norma legal que -al igual que cualquier otra norma legal que satisface los respectivos criterios de validez - forma parte del derecho positivo, debiendo, por lo mismo, ser aplicada a un caso concreto de verificarse sus respectivas condiciones de aplicación ${ }^{71}$. Una característica fundamental de toda cláusula general como la buena fe contractual es de hecho vista en la circunstancia de que se trata de una norma jurídica formulada en una disposición legal, la que debe ser aplicada al igual que cualquier otra disposición legislada que forma parte del derecho vigente ${ }^{72}$. En este sentido, en la medida en que es el propio legislador quien opta por regular gran parte del contenido implícito de la relación contractual mediante una norma jurídica de esa especie en vez de establecer una catálogo de normas jurídicas más detalladas, de surgir un conflicto con ocasión de esa relación y verificarse la respectivas

\footnotetext{
${ }^{69}$ Véase Hesselink (2011), p. 655 y ss. y 647 y ss.

${ }^{70}$ Wieacker (1956), p. 21; Werner (1966), p. 7.

${ }^{71}$ Auer (2005), p. 3; Bydlinsky (1990), p. 199.

${ }^{72}$ Grundmann (2006), p. 3.
} 
condiciones de aplicación, el juez debe necesariamente atender a lo ordenado por el legislador al introducir la respectiva cláusula general, lo que en esencia implica atender a las directivas y guías de conducta a las que remite la buena fe contractual, para derivar de las mismas el respectivo deber de conducta o efecto jurídico específico. La circunstancia de que la buena fe contractual se distancie de una aplicación meramente mecánica del derecho y suponga especiales espacios de discreción judicial no significa en ese sentido que, por esa sola razón, la jurisprudencia deje de ser una servidora de la ley en la resolución de los conflictos de relevancia jurídica vinculados a las relaciones contractuales donde resulta aplicable el estándar del contratante leal y honesto. En la aplicación de la buena fe contractual a un conflicto particular los tribunales de justicia deben, por lo mismo, sujetarse siempre a lo ordenando por el legislador ${ }^{73}$.

\section{La existencia de una potestad delegada dirigida} como presupuesto de aplicación de la buena fe contractual

Las cláusulas generales como la buena fe contractual constituyen una técnica de regulación del comportamiento en que es el propio legislador quien adopta la decisión de ordenar las relaciones jurídicas mediante un 134 estándar o modelo general de conducta en lugar de establecer una regulación más precisa y detallada de la relación contractual. La razón o motivo fundamental por el cual el legislador adopta esa decisión es porque gran parte de los deberes de comportamiento y demás efectos jurídicos que rigen una determinada relación contractual solo pueden ser adoptados sobre la base de hechos más precisos, y a la luz de todas las circunstancias que en concreto pueden resultar relevantes para la configuración del contrato. En atención a que esos hechos y circunstancias concretas resultan por definición desconocidos para el legislador al momento de dictar la ley, su única alternativa a ese respecto es regular el comportamiento mediante un estándar general de conducta y, por esa vía, traspasar o delegar en el juez la tarea de definir esos deberes y demás efectos jurídicos específicos en cada caso concreto. Lo anterior es el único camino abierto al legislador, salvo que se esté dispuesto a asumir los riesgos y las desventajas que necesariamente conllevan una regulación más rígida, fragmentaria e inacabada de la institución del contrato. La inconmensurabilidad, complejidad e imprevisibilidad de los hechos y circunstancias concretas que pueden resultar relevantes para la configuración de la relación contractual, así como el dinamismo y la movilidad de las transformaciones sociales y económicas que inciden en el contrato, se imponen de esta manera al

${ }^{73}$ Wieacker (1956), p. 8. 
legislador, forzándolo a regular el comportamiento de las partes contratantes mediante una cláusula general como la buena fe contractual.

En atención a que la aplicación de la buena fe contractual necesariamente implica la determinación en concreto por el juez de los deberes de conducta y demás efectos jurídicos específicos que se derivan del estándar del contratante leal y honesto, la ordenación del contrato mediante la buena fe presupone por definición la existencia de una particular potestad del juez para determinar esos deberes de conducta y demás efectos jurídicos específicos en cada caso particular. Atendido que la existencia y ejercicio de una potestad de esa especie es propia y característica del proceso de concreción de las cláusulas generales, puede sostenerse que la regulación del comportamiento mediante una cláusula general presupone por definición delegar en la judicatura la potestad de precisar una serie aspectos específicos de un determinado ámbito de relaciones jurídicas que resultan relevantes para el derecho privado ${ }^{74}$. La razón de ese traspaso o delegación en la figura del juez tiene su origen en que es este quien en ejercicio de la función jurisdiccional se confronta con los hechos, circunstancias concretas $\mathrm{y}$ transformaciones que resultaban imprevisibles e inconmensurables para el legislador al momento de dictar la ley, y que son los que determinan la introducción de una cláusula general como la buena fe contractual en el conjunto de normas jurídicas que configuran el derecho de contratos ${ }^{75}$.

En el ejercicio de la potestad que presupone la aplicación de la buena fe contractual el juez debe siempre efectuar una evaluación y ponderación de todos los hechos y circunstancias que en concreto resultan relevantes, para, de ese modo, precisar los deberes de conducta y demás efectos jurídicos específicos que configuran gran parte del contenido implícito del contrato. En la realización de esa tarea el juez se encuentra siempre en la necesidad de efectuar un especial acto de valoración, lo que significa que los diferentes hechos y circunstancias que en concreto resultan jurídicamente relevantes para la configuración de la relación contractual deben ser ponderados y evaluados a la luz de ciertos valores y fines, para de esa manera poner al descubierto y precisar el deber de conducta o efecto jurídico específico que rige una particular relación contractual. En la determinación de esos valores y fines el juez no es, sin embargo, libre, en el sentido de poder invocar las consideraciones normativas que estime pertinentes de conformidad a su propio juicio personal y convicciones subjetivas, sino que debe siempre recurrir a los valores y fines a los que remite el estándar del contratante leal y honesto, que son aquellos que se encuentran en las bases de la institución del contrato, y que configuran

\footnotetext{
${ }^{74}$ Véase RöThel (2004), p. 130.

${ }^{75}$ Véase Engisch (2010), p. 152; Beater (1994), p. 86; Werner (1966), p. 19 y ss.
} 
el contenido sustantivo de la buena fe contractual. En ese sentido, puede sostenerse que se trata de un conjunto de valores y fines objetivos, que tienen vigencia jurídica y, por lo mismo, se imponen al juez en la concreción de la buena fe contractual ${ }^{76}$.

En la medida que al aplicar la buena fe contractual a un caso particular se concretan los valores y fines previamente establecidos y predeterminados por el legislador, la tarea del juez se limita en realidad a realizar o materializar el programa de valores y fines previamente definido en la ley, traduciéndolo o condensándolo en un deber de comportamiento o efecto jurídico específico ${ }^{77}$. En la realización o materialización de ese programa el juez se pone en el lugar del legislador y, siguiendo sus directrices, actúa de manera análoga a como este lo haría de confrontarse con los hechos y circunstancias concretas que resultan relevantes para definir el contenido implícito del contrato. En esa tarea, su actuación se asemeja en cierto sentido a la acción del legislador cuando establece las normas dispositivas que típicamente integran el contenido de los diferentes contratos en silencio de los contratantes, las cuales atienden a circunstancias más acotadas, y tienen en su gran mayoría su origen histórico en desarrollos jurisprudenciales fundados en la buena fe contractual, razón por la cual esas normas dispositivas pueden ser tenidas en general por una concreción legal de la buena fe 136 contractual, en el sentido de dar cuenta de lo que constituye el contenido implícito de ciertos aspectos específicos del contrato de conformidad al estándar del contratante leal y honesto ${ }^{78}$.

Lo anterior configura en general la tarea del juez en la aplicación judicial de la buena fe, sea que mediante su concreción se trate de determinar el contenido y regulación de una específica relación contractual a través de la interpretación del acuerdo de las partes, de su integración, de la exclusión del ejercicio de ciertos derechos y facultades contractuales en razón de su carácter abusivo y por completo desleal o, en el extremo, de la modificación o corrección de una determinada regla contractual en razón de circunstancias por completo excepcionales que inciden de una manera desproporcionada en la ejecución del contrato ${ }^{79}$.

En la medida que, por una parte, la regulación del comportamiento de los contratantes mediante la buena fe contractual implica que el legislador traspasa o delega en el juez la potestad de definir en concreto los específicos deberes de conducta y demás efectos jurídicos que rigen la relación contractual y, por la otra, en el ejercicio de esa potestad el juez

\footnotetext{
${ }^{76}$ Larenz (1991), p. 288 y ss.; Engisch (2010), p. 144.

${ }^{77}$ Cfr. Wieacker (1956), p. 22.

${ }^{78}$ Véase Guzmán (2002), p. 14.

${ }^{79}$ Cfr. Schubert (2016), nº 50 y ss.; Looschelders y Olzen (2015), n. ${ }^{\circ} 144$.
} 
debe guiarse por los valores y fines previamente definidos por el propio legislador, puede sostenerse que la aplicación de la buena fe contractual a un caso particular presupone por parte del juez la existencia y el ejercicio de una potestad delegada, pero estrictamente dirigida. La señalada potestad se encuentra delegada en el juez, en la medida que la facultad de definir los deberes de conducta y demás efectos jurídicos que configuran el contenido implícito del contrato corresponde típicamente al legislador. Esa potestad delegada se encuentra, sin embargo, estrictamente dirigida, en la medida que su ejercicio presupone considerar solamente las directivas predeterminadas por el propio legislador, para a la luz de las mismas, y con consideración de todas las particularidades del caso concreto, definir el único deber de conducta y efecto jurídico específico que pueden ser tenidos por correctos en la configuración del contenido implícito del contrato $^{80}$.

En el ejercicio de la labor que presupone la aplicación de la buena fe contractual el juez realiza una tarea eminentemente normativa, orientada a definir y poner al descubierto la regla contractual que debió haber observado cada contratante en las circunstancias concretas, de manera de no comportarse abusivamente y no defraudar las legítimas expectativas de conducta de la parte contraria, en atención a la finalidad económica o propósito práctico de la convención. De modo análogo a como sucede con la determinación judicial de la culpa, al concretizar la buena fe contractual el juez no crea ex post un deber de conducta o efecto jurídico que pueda tenerse por sorpresivo o novedoso para las partes, sino que se limita a precisar un deber de conducta o efecto jurídico específico que cada uno de los contratantes pudo y debió reconocer ex ante como contenido implícito del contrato, en atención a su finalidad económica o propósito práctico. La buena fe contractual importa, por lo mismo, un estándar de conducta objetivo, el que es solamente concretizado y precisado por el juez, quien se limita a definir en un caso particular el comportamiento que cada parte contratante debió observar y seguir como guía de su conducta con ocasión de la relación contractual. En razón de su propia naturaleza, en esa tarea aplicación y creación del derecho fluyen en cierto sentido en una sola y misma actividad, cuestión que explica por qué los casos particulares en que la buena fe es concretizada en una regla individual resultan tan determinantes para los efectos de dotarla de contenido y mostrar su significado y alcance ${ }^{81}$. En ese sentido debe ser entendida la clásica expresión de Franz Wieacker, de que cada acto de aplicación de la buena fe contractual participa en la realización y desenvolvimiento del derecho de contratos, de modo

${ }^{80}$ Véase Raz (1996), p. 244 y ss.; Engisch (2010), p. 152; SCHMidt (2009), p. 30 y ss.

${ }^{81}$ LARENZ (1991), pp. 224 y 293. 
análogo a como cada golpe de aguja participa en la formación del tejido, prosiguiendo in actu una línea cuya dirección no podía ser aún trazada ${ }^{82}$.

Lo antes señalado no solo da cuenta de las particularidades de la concreción de la buena fe contractual, sino que, también, de que su aplicación por los tribunales de justicia a un caso particular implica la consideración de una serie de aspectos de hecho para los efectos de aplicar el derecho, de manera de que se trata de una cuestión estrictamente jurídica, razón por la cual cae inequívocamente bajo el control de la Corte Suprema a través del recurso de casación en el fondo ${ }^{83}$, cuestión que es también entendida de ese modo en el derecho comparado ${ }^{84}$.

\section{La función de la doctrina jurídica: \\ control crítico y sistematización de las aplicaciones de la buena fe contractual}

En los términos antes señalados, la aplicación de la buena fe contractual a un caso particular implica la existencia de una sola y única decisión correcta, en el sentido de que de conformidad al estándar del contratante leal y honesto solo uno es el deber de conducta o efecto jurídico que puede tenerse por correcto en la configuración de una específica relación obligatoria. Sin perjuicio de ello, la aplicación de la buena fe contractual 138 constituye una tarea que necesariamente abre espacios significativos a la discreción judicial, lo que tiene su origen en que su concreción importa la precisión de un deber de conducta o efecto jurídico específico hasta entonces indeterminado, frente a un conjunto de hechos particulares que inciden relevantemente en el contrato, cuestión que por su propia naturaleza sobrepasa las dificultades asociadas a la aplicación judicial de una regla legal previamente definida con detalle por el propio legislador tanto en sus presupuestos como en sus efectos. En razón de su contenido y la forma jurídica que adopta, existe en este sentido un especial espacio residual de discreción judicial en la aplicación de la buena fe contractual, el que no resulta posible eliminar del todo, pudiendo tenerse, por lo mismo, por aparentemente irreductible ${ }^{85}$. La existencia de ese espacio residual de discreción judicial significa que en la aplicación de la buena fe contractual existe una rango de decisiones que pueden ser razonablemente adoptadas y defendidas frente a un caso particular, en el sentido de que un determinado deber de conducta o efecto jurídico específico es el que rige una relación contractual a la luz de las directivas que dotan

\footnotetext{
${ }^{82}$ Wieacker (1956), p. 15

${ }^{83}$ Así también López y Elorriaga (2017), p. 438; Corral (2010), p. 97.

${ }^{84}$ Looschelders y Olzen (2015), n. ${ }^{\circ} 331$; MiQuel (1991), p. 39.

${ }^{85}$ ENGisch (2010), p. 152; LaRenz (1991), p. 93 y ss.
} 
de contenido el estándar del contratante leal y honesto ${ }^{86}$. Los valores y fines que se encuentran en las bases de la institución contractual y a los que remite la buena fe, son en ese sentido objeto de un acuerdo universal mientras permanecen indeterminados (honestidad, lealtad, exclusión del abuso, consideración del otro, protección de la confianza), sin perjuicio de que cuando se trata de precisar sus efectos y aplicarlos a una situación o relación jurídica concreta, suelen aparecer desacuerdos ${ }^{87}$. Lo señalado no significa, sin embargo, que cualquier decisión pueda ser adoptada como legítima con fundamento en la buena fe contractual, pero sí que existe un rango acotado de decisiones que resultan razonablemente defendibles a la luz de ese estándar jurídico de conducta. Lo anterior debe entenderse sin perjuicio de que dentro del conjunto de resultados que conforman el rango de decisiones razonablemente defendibles, una sola decisión es la portadora de la regla contractual correcta de conformidad a la buena fe contractual, en el sentido de ser la regla que de manera más adecuada materializa y se condice con los valores y fines remitidos por la buena fe. La decisión o regla contractual correcta es en este sentido conceptualmente más acotada que la decisión o regla contractual defendible, ya que mientras la decisión o regla contractual correcta es siempre defendible, no toda decisión o regla contractual defendible es también la correcta ${ }^{88}$. La circunstancia referida, esto es, que la aplicación de la buena fe implique la existencia de una sola regla contractual adecuada, es la que tiene por efecto que no solamente el estándar de comportamiento en sí, sino que, también, la aplicación de ese estándar a un caso particular tenga la pretensión de ser objetiva ${ }^{89}$.

En la definición de lo que constituye el deber de comportamiento o efecto jurídico específico que rige una determinada constelación de hechos a la luz de lo ordenado por el estándar del contratante leal y honesto, una tarea fundamental corresponde a la doctrina jurídica, la que a través de la permanente discusión, el contraste de pareceres y un análisis crítico de las decisiones judiciales que aplican la buena fe contractual a un caso particular, puede contribuir a delimitar y precisar su contenido, disciplinando de esta manera la actividad de los tribunales de justicia en la aplicación y desarrollo del derecho de $\operatorname{contratos}^{90}$. El señalado análisis

${ }^{86}$ Cfr. MacCormick (2000), pp. 408 y 414; Stone (1964), p. 264.

${ }^{87}$ Véase Perelman (1977), p. 40, referido en MacCormick (2000), p. 402; Duve (2007), n. ${ }^{\circ}$ 20, p. 292.

${ }^{88}$ ENGisch (2010), p. 173; LARENZ (1991), p. 294.

${ }^{89}$ LARenZ (1991), p. 291, con referencia a Frankena (1972), p. 131.

${ }^{90}$ Véase Picker (2012), p. 85 y ss. y 110 y ss.; Picker (1988), p. 1 y ss. y 62 y ss.; Picker (1984), p. 153 y ss. Extraordinariamente crítico respecto de la efectiva existencia de un control y posibilidad de disciplinamiento de la jurisprudencia por la dogmática jurídica, RüTHERS (2014), p. 47 y ss. 
crítico de las decisiones de los tribunales de justicia, su constante revisión y su permanente confrontación con las directivas que dotan de contenido el estándar del contratante leal y honesto, permiten de esta manera identificar cuál es el deber de comportamiento y efecto jurídico específico que debe regir en una determinada constelación de hechos que resultan relevantes para la relación contractual. El diálogo permanente entre jurisprudencia y doctrina jurídica, así como el discernimiento práctico y la permanente confrontación con ciertos hechos y circunstancias particulares que se van reiterando en la configuración de diferentes relaciones contractuales, permite consolidar la regla contractual que resulta adecuada de conformidad con la buena fe contractual, en el sentido de ser la que efectivamente realiza el programa de valores y fines previamente definidos por el legislador para la institución del contrato.

La decisión que aplica correctamente la buena fe contractual puede tenerse de conformidad a lo señalado por portadora de una individuación o concreción del orden valores y fines al que remite la buena fe, teniendo una importancia que muchas veces trasciende al caso particular, al dotar un concepto jurídico indeterminado y abstracto -como la buena fe contractual- con un contenido determinado y concreto. En el sentido referido, los casos particulares que se van resolviendo correctamente por referen140 cia a la buena fe contractual van precisando su específico significado, el que se va poniendo continuamente al descubierto en diferentes casos y contextos particulares, los que van mostrando las exigencias impuestas a los contratantes por ese estándar de conducta. La circunstancia descrita tiene, por consecuencia, que la sistematización de las sentencias judiciales que aplican la buena fe contractual, así como su ordenación en diferentes grupos o constelaciones de casos de acuerdo con criterios específicos, sea de una extraordinaria importancia, tanto para el conocimiento como para el desarrollo del derecho de contratos. Lo primero, por cuanto la buena fe contractual constituye una categoría jurídica de referencia indeterminada, cuyo significado se muestra especialmente en casos y contextos particulares, de manera tal que esos casos y contextos particulares resultan esenciales para los efectos de conocer su significado. Lo segundo, por cuanto esas decisiones particulares pueden, a su vez, ser generalizadas, de manera de ir dando forma a verdaderos tipos jurídicos, cada vez más precisos y acotados, que sirven de antecedente para la resolución de casos análogos, sin perjuicios de que en ellos primen y sean siempre consideradas todas sus circunstancias particulares. La configuración de tipos más precisos y acotados que concretizan la buena fe contractual no tiene pretensiones de exhaustividad, en el sentido de agotar todos sus supuestos de aplicación. En general, muchos tipos pueden superponerse en sus fronteras, quedando por definición siempre abierta la posibilidad de nuevas constelaciones de 
hechos que en razón de sus particularidades o las transformaciones económicas y sociales de que dan cuenta, no resultan subsumibles bajo ninguno de los tipos previamente delineados. Aun en esos supuestos, sin embargo, los tipos previamente delineados ofrecen una guía en la resolución de esos casos, al dar cuenta mediante diferentes concreciones del significado de las directrices de conducta que en general la buena fe contractual impone a los contratantes. La sistematización y ordenación de los casos típicos que constituyen aplicaciones de la buena fe contractual favorece de esta manera no solo el mismo tratamiento de casos análogos, sino que sirve, también, de guía para la resolución de casos nuevos, favoreciendo de esta manera la certeza jurídica y la calculabilidad de las decisiones judiciales. Por esa vía se reduce la arbitrariedad judicial y el vulgarismo jurídico, en cuanto riesgos asociados a la regulación del comportamiento mediante una cláusula general como buena fe contractual ${ }^{91}$.

La tarea señalada, esto es, el control crítico, la discusión y la sistematización de las diferentes aplicaciones judiciales de la buena fe contractual, es por definición una función que corresponde y solo puede ser satisfecha por la doctrina jurídica, presuponiendo la vigencia de la buena fe contractual, por lo mismo, tanto un cierto refinamiento del estamento de los juristas, como un diálogo fluido de ese estamento con la jurisprudencia ${ }^{92}$.

\section{La buena fe como fundamento de una aplicación coherente y del desarrollo interno del derecho de contratos}

La antes señalada interacción entre legislación y judicatura, por una parte, y entre judicatura y doctrina jurídica, por la otra, que implica la existencia y concreción de la buena fe contractual, expresa un particular modo de aplicación, desenvolvimiento y desarrollo del derecho de contratos en nuestra tradición jurídica, el que por esa vía puede continuamente generar la regla jurídica adecuada para regular el contenido de las diferentes relaciones contractuales, con consideración de todas sus particularidades, y de todos los cambios y transformaciones sociales que resultan relevantes para las diferentes relaciones comerciales y económicas que se canalizan a través de la figura del contrato. La buena fe contractual permite, de esta manera, por una parte, morigerar la aplicación puramente formal del derecho de contratos, cuando en atención a todas las particularidades del caso concreto, esa aplicación lleva a resultados insatisfactorios y, por la

${ }^{91}$ Véase Beater (1994), p. 82 y ss.; Miquel (1997), p. 309 y ss; Miquel (1991), p. 38; De la MaZa (2014), p. 221 y ss.

${ }^{92}$ Véase RÜthers, Fischer y BIrk (2011), p. 195 y ss., sobre las funciones de la dogmática jurídica. 
otra, permite adaptar el derecho de contratos a hechos y circunstancias nuevas e imprevisibles, que resultan de la constante movilidad social y económica. De este modo, la buena fe contractual da cuenta de un especial dinamismo interno del derecho de contratos, constituyendo el medio que permite su continuo desenvolvimiento y desarrollo desde adentro, de una manera que resulta consistente con los valores y fines que lo fundamen$\tan$.

En suma, al insertar una cláusula general como la buena fe contractual en el conjunto de normas que configuran el derecho de contratos, el legislador traspasa o delega en la judicatura la tarea de determinar en concreto, y de acuerdo con un conjunto de valores y fines previamente definidos, los deberes de conducta y demás efectos jurídicos específicos que rigen una determinada relación contractual. Lo anterior, en atención a que le resulta imposible prever, tanto las circunstancias particulares que resultan relevantes para el contrato como todos los hechos que configuran el desarrollo del futuro e inciden en el mismo. En el cumplimiento de esa tarea, la jurisprudencia, disciplinada por el antes referido control crítico de la doctrina jurídica, lleva adelante la aplicación, desenvolvimiento y desarrollo del derecho de contratos en diferentes casos particulares, siguiendo los valores y fines predeterminadas por el propio legislador 142 para la institución contractual, de manera tal que el derecho de contratos se aplica, desenvuelve y desarrolla en una dirección y sentido que resulta consistente con sus fundamentos. De esta manera, mediante la buena fe contractual, el derecho de contratos dispone de un instrumento que permite tanto su aplicación a un caso concreto como su movilidad y dinamismo interno, de una manera que resulta coherente con los valores y fines que están en sus bases más elementales. La buena fe se configura de ese modo como un pilar fundamental de la institución del contrato, cuya flexibilidad, adaptabilidad y movilidad resultan indispensable para que este pueda desempeñar adecuadamente su función más básica y esencial, en cuanto instrumento dinámico de la economía, que permite el adecuado desenvolvimiento y desarrollo de las diferentes relaciones de intercambio y cooperación que configuran el comercio ${ }^{93}$.

\section{Conclusiones}

La buena fe contractual constituye un concepto jurídico de referencia indeterminada, que remite a un conjunto de directivas que no han sido expresadas en el acuerdo contractual, relativas a la lealtad, honestidad y

${ }^{93}$ Cfr. Raz (1996), p. 238 y ss. 
consideración mutua que las partes contratantes pueden razonablemente esperar en su comportamiento recíproco en atención a la especial relación que se ha formado entre ellas en virtud del contrato. La observancia de ese conjunto de directivas presupone actuar de conformidad al estándar del contratante leal y honesto, cuya principal particularidad es comportarse de un modo que considera no solo los propios intereses, sino que, también, los de la parte contraria, para los efectos de satisfacer la finalidad económica o propósito práctico que subyace a la convención, de manera de no comportarse abusivamente y de no defraudar las legítimas expectativas de conducta de la contraparte contractual. Mientras la autonomía privada se refiere a todos los aspectos explícitamente convenidos por los contratantes, la buena fe se refiere a todos aquellos aspectos que no han sido expresamente acordados por la partes, pero conforman implícitamente el contenido del contrato, de manera tal que son presupuestos por los contratantes durante todo el desarrollo y en todo momento de la relación contractual, en atención al sentido económico y la finalidad práctica del negocio.

El valor central que en último término subyace a la buena fe contractual en cuanto principio ordenador de la relación obligatoria es la confianza que implica la relación de intercambio y cooperación que subyace al contrato. La existencia y protección de esa confianza constituye un presupuesto básico e indispensable para la realización de intercambios y el desarrollo del tráfico jurídico en general, sin la cual el comercio y gran parte de las demás relaciones económicas que se canalizan a través del contrato no resultan siquiera imaginables. La autonomía privada tiene en ese sentido un necesario correlato y presupuesto de ejercicio en un cierto grado de confianza depositado en la contraparte contractual, la que en su sentido más elemental se expresa en la expectativa de que la palabra empeñada será observada y la promesa contractual cumplida, cuestión que coincide con el significado más originario de la buena fe contractual, en cuanto sentirse vinculado por la propia declaración en razón de la confianza creada en la otra parte. La confianza expresada en la buena fe contractual no se agota, sin embargo, en esa sola circunstancia, sino que comprende un conjunto o abanico mucho más amplio de expectativas implícitas respecto de lo que puede tenerse por el comportamiento exigible a las partes contratantes en sus tratos recíprocos con ocasión del desarrollo y ejecución del contrato. Esas expectativas implícitas tienen una incidencia directa en la interpretación de la convención, en su integración, en la limitación de ciertas conductas de los contratantes e, incluso, en la eventual corrección o modificación del contenido de la regla contractual, siendo la intensidad de la confianza depositada en la contraparte y, por lo mismo, la relevancia ordenadora de la buena fe, variable en función de la naturaleza y las particularidades del negocio que subyacen a la convención. 
El art. 1546 del Código Civil, en cuanto disposición legal que reconoce con alcance general la buena fe contractual, adopta la forma jurídica de una cláusula general, lo que esencialmente implica una técnica de regulación del comportamiento caracterizada por situarse en el extremo contrario a una ordenación estrictamente casuística y fragmentada de un cierto ámbito de relaciones de derecho privado. Las cláusulas generales tienen la particularidad de definir su ámbito de aplicación de un modo extraordinariamente amplio, y de fijar de un modo relativamente indeterminado los deberes de comportamiento y demás efectos jurídicos asociados a la realización de la respectiva hipótesis legal, razón por la cual suelen destacarse por su generalidad, su alto nivel de abstracción y su significativo grado de indeterminación conceptual. El verdadero rasgo distintivo de las cláusulas generales puede ser visto, sin embargo, en que no establecen con precisión los deberes de comportamiento y demás efectos jurídicos específicamente ordenados para cada una de las hipótesis de hecho comprendidas en su ámbito de aplicación, sino que, en su lugar, establecen un estándar o modelo de conducta que indica las directivas de comportamiento que deben ser observadas en cada una de esas innumerables hipótesis. La determinación del deber de conducta o efecto jurídico específico que rige una específica relación jurídica solo 144 puede efectuarse en un estadio posterior, sobre la base de circunstancias más acotadas, y a la luz de las directivas que dotan el referido estándar de comportamiento de contenido. La gran ventaja de ordenar la relación contractual mediante una norma jurídica que asume la forma de una cláusula general, como la contenida en el art. 1546 del Código Civil, es su enorme plasticidad y flexibilidad, la que le permite aplicar el derecho de contratos de un modo que sea consistente con el sentido y finalidad de la convención, cuando una aplicación puramente formal de la ley lleva a un resultado por completo insatisfactorio, teniendo, además, una especial aptitud para resolver nuevos supuestos de hecho no previstos por la ley y que son consecuencia de las transformaciones tecnológicas, económicas y sociales que inciden relevantemente en la institución del contrato. El gran riesgo de la regulación del comportamiento de los contratantes mediante la buena fe contractual radica en los significativos espacios de discreción que su aplicación presupone para los jueces, lo que configura una potencial fuente de inseguridad jurídica, arbitrariedad judicial y desformalización del derecho de contratos. Sin perjuicio de esos riesgos, una vez alcanzado un determinado estadio de desarrollo, la aplicación estricta y puramente formal de las normas jurídicas que conforman el derecho de contratos debe ser necesariamente complementada por una cláusula general como la buena fe contractual, que le otorgue la suficiente flexibilidad, adaptabilidad y dinamismo, para los efectos de juzgar todas las circunstancias 
especiales que inciden relevantemente en la relación contractual. Ese diseño presupone tanto un especial refinamiento de la jurisprudencia en la aplicación de la buena fe contractual como un freno y control crítico de ese proceso por la doctrina jurídica, como único modo de evitar los riesgos asociados a una mayor preponderancia de la buena fe contractual en la ordenación de la relación obligatoria surgida del acto convencional.

En razón de su particular contenido y la forma jurídica que adopta, la buena fe contractual no se deja aplicar mecánicamente mediante un simple juicio lógico de subsunción, cuestión que no obsta a la esencial vinculación del juez a la ley en su concreción en un caso particular. La disposición legal que consagra la buena fe contractual forma parte del derecho positivo y debe ser aplicada al igual que cualquier otra disposición legal que comparte esa cualidad de verificarse su respectivo presupuesto de aplicación, debiendo, por lo mismo, estarse a lo ordenado por el legislador al introducir la respectiva cláusula general, lo que en esencia implica atender a las respectivas directivas las que remite la buena fe contractual, para derivar de las mismas el respectivo deber de conducta o efecto jurídico específico que rige a los contratantes. Los planteamientos que asumen una creación libre del derecho privado con fundamento en la buena fe contractual deben ser por lo mismo rechazados.

La razón por la cual el legislador recurre a la buena fe en la ordenación de la relación obligatoria radica en la imposibilidad de prever la inconmensurable cantidad de circunstancias concretas y transformaciones futuras que resultan relevantes para la relación contractual, lo que se traduce en la incapacidad de la ley de formular previamente y de manera exhaustiva todos los supuestos y todos los deberes de conducta y demás efectos jurídicos que rigen la relación contractual. En esas circunstancias, salvo que se esté dispuesta a asumir los costos y las desventajas que necesariamente conlleva una regulación más rígida y fragmentaria del contrato, el único camino abierto para el legislador consiste en regular el comportamiento mediante un estándar de conducta, lo que en esencia implica traspasar o delegar en el juez la potestad de definir y precisar esos deberes de conducta y demás efectos jurídicos específicos en cada caso particular, una vez verificadas las referidas circunstancias concretas y transformaciones que resultaban imprevisibles para el legislador al momento de dictar la ley, y que son los que determinan la introducción de una cláusula general como la buena fe en el conjunto de normas que configuran el derecho de contratos. La aplicación de la buena fe presupone, de este modo, necesariamente, el ejercicio de una potestad delegada en el juez para definir en concreto una serie de deberes de conducta y demás efectos jurídicos que configuran el contenido implícito de una determinada relación contractual. En el ejercicio de esa potestad el juez debe siempre efectuar un 
especial acto de valoración, lo que significa que los diferentes hechos y circunstancias que en concreto resultan relevantes para la configuración de la relación contractual deben ser ponderados y evaluados a la luz de ciertos valores y fines, para por esa vía poner al descubierto y precisar los deberes de conducta y demás efectos jurídicos que rigen a los contratantes. En la determinación de esos valores y fines el juez no es, sin embargo, libre, sino que debe recurrir a aquellos remitidos por el estándar del contratante leal y honesto, que se encuentra en las bases de la institución contractual y que, en definitiva, configuran el contenido sustantivo de la buena fe. En la medida que la regulación del comportamiento mediante la buena fe implica que el legislador traspasa o delega en el juez la tarea de definir en concreto los deberes de conducta y demás efectos jurídicos que rigen la relación contractual, pero que en el ejercicio de esa potestad el juez debe guiarse y observar las directivas previamente definidas por el propio legislador, puede sostenerse que la aplicación de la buena fe contractual a un caso particular presupone por parte del juez el ejercicio de una potestad delegada, pero estrictamente dirigida, orientada a concretizar el estándar del contratante leal y honesto. En esas circunstancias, al aplicar la buena contractual a un caso particular, el juez se limita a realizar o materializar el programa de fines y valores previamente definido en la 146 ley, traduciéndolo o condensándolo en un deber de comportamiento o efecto jurídico específico. En razón de su propia naturaleza, en esa tarea aplicación y creación del derecho fluyen en una sola y misma actividad.

En razón de su particular constitución, la aplicación de la buena fe contractual abre necesariamente ciertos espacios irreductibles a la discreción judicial, lo que se traduce en la existencia de un rango de decisiones que pueden ser razonablemente adoptadas con fundamento en la misma, sin perjuicio de que solo una de esas decisiones sea la propiamente correcta, en el sentido de materializar de manera más adecuada el programa de fines y valores previamente definidos por el legislador y que subyacen a la institución del contrato. Lo anterior significa que no solamente el estándar del contratante leal y honesto en sí, sino que, también, la aplicación de ese estándar a un caso particular, tienen la pretensión de ser objetivos. En la definición de lo que constituye lo específicamente ordenado por la buena fe contractual una tarea fundamental corresponde a la doctrina jurídica, la que a través de la permanente discusión, el contraste de pareceres y un análisis crítico de las respectivas decisiones judiciales puede contribuir a delinear y precisar su contenido, disciplinado de esta manera la actividad de los tribunales de justicia. El diálogo fluido y permanente entre jurisprudencia y doctrina permite de esta manera encontrar y consolidar la regla jurídica adecuada de conformidad con la buena fe contractual, que es aquella que de manera más correcta realiza y se deja incorporar en la 
institución del contrato. En ese orden de ideas, la decisión judicial que aplica correctamente la buena fe contractual tiene una importancia que trasciende al caso particular, en la medida que el conjunto de esas decisiones van mostrando y poniendo al descubierto cuáles son las exigencias impuestas a los contratantes por el estándar del contratante leal y honesto. Por lo mismo, la sistematización y ordenación de esas sentencias judiciales en constelaciones o grupos de casos resulta de extraordinario valor, en la medida que permite conocer el significado de la buena fe e ir dando forma a figuras típicas cada vez más precisas y acotadas, que sirven de antecedentes para la resolución de casos análogos e, incluso, nuevos, sin perjuicio de que en ellos primen siempre sus circunstancias particulares. Mediante la antes referida sistematización se favorece de esa manera la certeza jurídica y calculabilidad de las decisiones judiciales, reduciéndose los riesgos asociados a la regulación del comportamiento mediante una cláusula general como la buena de contractual.

La interacción descrita entre legislación y judicatura, por una parte, y entre judicatura y doctrina jurídica, por la otra, que implica la existencia y concreción de la buena fe contractual, es una consecuencia de la irremediable falta de exhaustividad de las demás normas legales que conforman la institución contractual, dando cuenta de que, mediante la misma, el derecho privado dispone de un instrumento que cumple dos tareas por completo esenciales: en primer lugar, la buena fe permite morigerar la aplicación puramente formal del derecho de contratos, cuando en atención a todas las circunstancias particulares del caso concreto esa aplicación lleva a resultados por completo insatisfactorios y, en segundo lugar, la buena fe da lugar a un especial dinamismo interno del derecho de contratos, constituyendo el medio que permite su continuo desarrollo y desenvolvimiento desde adentro, de una manera que resulta consistente con los valores y fines que lo fundamentan.

\section{Bibliografía CITADA}

Auer, Marietta (2005). Materialisierung, Flexibilisierung, Richterfreiheit. Generalklauseln im Spiegel der Antinomien des Privatrechtsdenkens. Tübingen: Mohr Siebeck.

Barros Bourie, Enrique (1983). "Derecho y moral. Consideraciones a propósito del derecho civil y penal de los contratos". Revista de Derecho y Jurisprudencia. Tomo 80. Primera parte. Santiago.

Barros Bourie, Enrique (2006). Tratado de responsabilidad extracontractual. Santiago: Editorial Jurídica de Chile.

BEATER, Axel (1994). "Generalklauseln und Fallgruppen”. Archiv für die civilistische Praxis. n. ${ }^{\circ}$ 194. Tübingen. 
Boetsch Gillet, Cristián (2011). La buena fe contractual. Santiago: Editorial Jurídica de Chile.

BYDLINSKI, Franz (1967). Privatautonomie und objektive Grundlagen des verpflichtenden Rechtsgeschäftes. Wien, New York: Springer Verlag.

Bydlinsky, Franz (1990). "Möglichkeiten und Grenzen der Präzisierung aktueller Generalklauseln", in Okko Behrends, Malte Diesselhorst, Ralf Dreier, (eds.), Rechtsdogmatik und praktische Vernunft. Symposium zum 80. Geburtstag von Franz Wieacker. Göttingen: Vandenhoeck \& Ruprecht.

Bydlinsky, Franz (2011). Juristische Methodenlehre und Rechtsbegriff. $2^{\mathrm{a}}$ ed. (reimpresión). Wien, New York: Springer Verlag.

Carrasco Perera, Ángel (2017). Derecho de Contratos. $2^{\text {a }}$ ed. Cizur Menor, Navarra: Thomson Reuters-Aranzadi.

Claro Solar, Luis (1937). Explicaciones de derecho civil chileno y comparado. Santiago: Imprenta Nascimiento. Tomo XI: De las obligaciones.

Corral Talciani, Hernán (2010). Contratos y daños por incumplimiento. Santiago: Abeledo Perrot-Legal Publishing.

De la Maza Gazmuri, Iñigo (2014). "La buena fe como dispositivo de ponderación”, en Iñigo De la Maza Gazmuri, Antonio Manuel Morales Moreno, Álvaro Vidal Olivares, Estudios de Derecho de Contratos. Santiago: Legal Publishing-Thomson Reuters.

148 Díez-Picazo, Luis (1986). "Prólogo", en Franz Wieacker, , El principio de buena fe. (trad.) José Luis Carro. Madrid: Editorial Civitas.

Díez-Picazo, Luis (2007). Fundamentos de Derecho Civil Patrimonial. $7^{\mathrm{a}}$ ed. Madrid: Civitas. Tomo I.

Duve, Thomas (2007). "§ 242. Leistung nach Treu und Glauben”, in Mathias Schmoeckel, Joachim Rückert \& Reinhard Zimmermann (eds.), Historischkritischer Kommentar zum BGB. Tübingen: Mohr Siebeck.

Eisenberg, Melvin A. (2001). "The Theory of Contracts", in Peter Benson (ed.), The Theory of Contract Law. Cambridge: University Press.

ENGISCH, Karl (2010). Einführung in das juristische Denken. $10^{\mathrm{a}}$ ed. Stuttgart: Verlag W. Kohlhammer.

EsSER, Josef \& Eike ScHMidT (1995). Schuldrecht. Allgemeiner Teil. $8^{\mathrm{a}}$ ed. Heidelberg: C. F. Müller. Tomo I/1

Eyzaguirre Baeza, Cristóbal y Javier Rodríguez Diez (2013). "Expansión y límites de la buena fe objetiva - A propósito del proyecto de principios latinoamericanos de derecho de los contratos". Revista Chilena de Derecho Privado. n. ${ }^{o}$ 21. Santiago.

Farnsworth, E. Allan (2004). Contracts. 4ª ed. New York: Aspen Publishers.

Ferreira Rubio, Delia Matilde (1984). La buena fe. El principio general en el derecho civil. Madrid: Editorial Montecorvo.

Fikentscher, Wolfgang (1975). Methoden des Rechts. In vergleichender Darstellung. Tübingen: J. C. B. Mohr (Paul Siebeck). Tomo I. 
Flume, Werner (1979). Allgemeiner Teil des Bürgerlichen Recths. $3^{\mathrm{a}}$ ed. Berlin, Heidelberg, New York: Springer Verlag. Tomo II: Das Rechtsgeschäft.

Frankena, William K. (1972). Analytische Ethik. München: Deutscher Taschenbuch Verlag.

Fried, Charles (2015). Contract as a promise. $2^{\text {a }}$ ed. Oxford: University Press.

Fueyo Laneri, Fernando (1990). Instituciones de Derecho Civil Moderno. Santiago: Editorial Jurídica de Chile.

GartsKa, Hansjürgen (1976). “Generalklauseln”, en Hans-Joachim KocH (ed.), Juristische Methodenlehre und analytische Philosophie. Kronberg/Ts.: Athenäum Verlag.

GonzÁlez Pérez, Jesus (2009). El principio general de la buena fe en el derecho administrativo. $5^{\mathrm{a}}$ ed. Cizur Menor, Navarra: Civitas-Thomson Reuters.

Grundmann, Stefan (2006). "General Standards and Principles, Clauses Générales, and Generalklausen in European Contract Law - A Survey", in Stefan Grundmann, Denis Mazeaud (eds.), General Clauses and Standards in European Contract Law. The Hague: Kluwer Law International.

Grüneberg, Christian (2018). “Comentario § 242 BGB”, in Palandt. Bürgerliches Gesetzbuch. 73a ed. München: C. H. Beck.

Guzmán Brito, Alejandro (2002). "La buena fe en el Código Civil de Chile". Revista Chilena de Derecho. Vol. 29. n. ${ }^{\circ}$ 1. Santiago.

HartKamp, Arthur (1995). "The Concept of Good Faith in the Unidroit Principles for International Commercial Contracts". Tulane Journal of International and Comparative Law. n. ${ }^{\circ}$ 3. New Orleans.

Hedemann, Justus Wilhelm (1933). Die Flucht in die Generalklauseln. Eine Gefahr für Recht und Staat. Tübingen: J.C.B. Mohr (Paul Siebeck).

HeInRICH, Christian (2000). Formale Freiheit und materiale Gerechtigkeit. Tübingen: Mohr Siebeck.

Hesselink, Martijn W. (2011). "The Concept of Good Faith”, in Arthur HaRTKAmP, Martjin W. Hesselink, Ewoud Hondius, Chantal MaK, Edgar Du Perron (eds.), Towards a European Civil Code. $4^{\mathrm{a}}$ ed. Alphen aan den Rijn: Kluwer Law International.

Kaser, Max y Knütel, Rolf (2008). Römisches Privatrecht. 19a ed. München: C. H. Beck.

KöHLER, Helmut (2017). BGB. Allgemeiner Teil. 41ª ed. München: C. H. Beck.

KöTz, Hein (2012). Vertragsrecht. $2^{\mathrm{a}}$ ed. Tübingen: Mohr Siebeck.

Kunkel, Wolfgang \& Martin Schermaier (2005). Römische Rechtsgeschichte. $14^{\mathrm{a}}$ ed. Köln: Böhlau Verlag.

LARENZ, Karl (1979). Richtiges Recht. Grundzüge einer Rechtsethik. München: C. H. Beck.

LARENZ, Karl (1987). Lehrbuch des Schuldrechts. 14ª ed. München: C. H. Beck. Tomo I: Allgemeiner Teil.

LARENZ, Karl (1991). Methodenlehre der Rechtswissenschaft. $6^{\mathrm{a}}$ ed. Berlin, Heidelberg, New York: Springer Verlag. 
LaRenz, Karl \& Claus-Wilhelm CANARIS (1994). Lehrbuch des Schuldrechts. $13^{\mathrm{a}}$ ed. München: C. H. Beck. Tomo II/2: Besonderer Teil.

Looschelders, Dirk \& Wolfgang Roth (1996). Juristische Methodik im Prozess der Rechtsgewinnung. Berlin: Duncker \& Humblot.

Looschelders, Dirk (2012). Schuldrecht. Besonderer Teil. $7^{\mathrm{a}}$ ed. München: Verlag Franz Vahlen.

Looschelders, Dirk (2014). Schuldrecht. Allgemeiner Teil. 12ª ed. München: Verlag Franz Vahlen.

Looschelders, Dirk \& Dirk Olzen, (2015). "Comentario § 242 BGB”, in J. von Staudingers Kommentar zum Bürgerlichen Gesetzbuch. Berlin: Sellier - de Gruyter.

López Santa María, Jorge y Fabián Elorriaga de Bonis (2017). Los contratos. Parte general. $6^{\mathrm{a}}$ ed. Santiago: Thomson Reuters.

MacCormick, Neil (2000), "Razonabilidad y objetividad" (trad.) Fernando Atria Lemaitre. Revista de Ciencias Sociales. n. ${ }^{\circ} 45$. Valparaíso.

Maurer, Hartmut y Waldhoff, Christian (2017), Allgemeines Verwaltungsrecht. 19 ${ }^{\mathrm{a}}$ ed. München: C. H. Beck.

Mayer-Maly, Theo (1981). "Wertungswandel und Privatrecht". Juristen Zeitung. n. ${ }^{\circ}$ 23/24. Tübingen.

Miller, Meredith R., (2010). "Contract Law, Party Sophistication and the New Formalism”. Missouri Law Review. Vol. 75. Columbia.

Miquel GonzÁlez, José María (1991). "Comentario artículo 7 inciso $1^{\circ}$ Código Civil español”, en Cándido Paz-Arez Rodríguez, Rodrigo Bercovitz, Luis Díez-Picazo Ponce de León y Pablo Salvador Cordech (dirs.), Ministerio de Justicia. Comentario del Código Civil. Madrid: Sec. General Técnica-Centro de Publicaciones. Tomo I.

MiQuel Gonzélez, José María (1997). "Cláusulas generales y desarrollo judicial del derecho". Anuario de la Facultad de Derecho de la Universidad Autónoma de Madrid. n. ${ }^{\circ}$ 1. Madrid.

Morales Moreno, Antonio Manuel (2006). “El 'propósito práctico’ y la idea de negocio jurídico en Federico de Castro", en Antonio Manuel Morales Moreno, La modernización del derecho de obligaciones. Cizur Menor, Navarra: Thomson-Civitas.

Онцу, Ansgar (2001). "Generalklauseln und Richterrecht”. Archiv für die civilistische Praxis. n. ${ }^{\circ}$ 201. Tübingen.

Peñallillo Arévalo, Daniel (2003). Las obligaciones. Reimpresión. Santiago: Editorial Jurídica de Chile.

Perelman, Chaim (1977). L'Empire Rhetorique: Rhetorique et Argumentation, 1977. Paris: J. Vrin.

Picker, Eduard (1984). "Richterrecht und Richterrechtsetzung". Juristen Zeitung. Tübingen.

Picker, Eduard (1988). "Richterrecht oder Rechtsdogmatik - Alternativen der Rechtsgewinnung”. Juristen Zeitung. Tübingen. 
Picker, Eduard (2012). "Richterrecht und Rechtsdogmatik. Zur rechtsdogmatischen Disziplinierung des Richterrechts", in Christian Bumke, (ed.), Richterrecht zwischen Gesetzesrecht und Rechtsgestaltung. Tübingen: Mohr Siebeck.

RAz, Joseph (1996). "The Inner Logic of the Law", in Joseph RAz, Ethics in the Public Domain. Essays in the Morality of Law and Politics. Reprint. Oxford: Clarendon Press.

RöTHEL, Anne (2004). Normkonkretisierung im Privatrecht. Tübingen: Mohr Siebeck.

RÜTHERs, Bernd, Christian FISCHER, Axel BIRK (2011). Rechtstheorie mit juristischer Methodenlehre. $6^{\text {a }}$ ed. München: C. H. Beck.

RüTHERs, Bernd (2012). Die unbegrenzte Auslegung. Zum Wandel der Privatrechtsordnung im Nationalsozialismus. $7^{\mathrm{a}}$ ed. Tübingen: Mohr Siebeck.

RüTHERs, Bernd (2014). Die heimliche Revolution vom Rechtsstaat zum Richterstaat. Tübingen: Mohr Siebeck.

SaAvedra Galleguillos, Francisco Javier (1996). "El principio general de la buena fe", en Instituciones Modernas de Derecho Civil. Santiago: Editorial Jurídica Cono Sur.

San Martín Neira, Lilian C. (2015). La Buena fe en la Jurisprudencia. Santiago: Thomson Reuters.

Schermaier, Martin Josef (2000). “Bona fides in Roman contract law”, in Reinhard Zimmermann, Simon Whittaker (eds.), Good Faith in European Contract Law. Cambridge: University Press.

Schmidt, Jürgen (1990), "Präzisierung des § 242 BGB - eine Daueraufgabe?”, in Okko Behrends, Malte Diesselhorst, Ralf Dreier (eds.), Rechtsdogmatik und praktische Vernunft. Symposium zum 80. Geburtstag von Franz Wieacker. Göttingen: Vandenhoeck \& Ruprecht.

Schмidt, Martin (2009). Konkretisierung von Generalklauseln im europäischen Privatrecht. Berlin: De Gruyter Recht.

Schopf Olea, Adrián (2015). "El ámbito de protección de la responsabilidad extracontractual y los daños puramente patrimoniales", en Âlvaro VIDAL Olivares, Gonzalo Severin Fuster y Claudia Mejías Alonzo (eds.), Estudios de Derecho Civil X. Santiago: Thomson Reuters.

Schopf OlEa, Adrián (2017). "Las diferencias funcionales entre la responsabilidad civil contractual y extracontractual", en Rodrigo BARRÍA DÍAZ, Alfredo Ferrante y Lilian C. San Martín Neira (eds.), Presente y futuro de la responsabilidad civil. Santiago: Thomson Reuters.

SchUbert, Claudia (2016). “Comentario § 242 BGB”. Münchner Kommentar zum $B G B .7^{\text {a }}$ ed. München: C. H. Beck.

Stempel, Christian (2016). Treu und Glauben im Unionsprivatrecht. Tübingen: Mohr Siebeck.

Stone, Julius (1964). Legal System and Lawyers' Reasoning. Stanford, California: University Press. 
TAPIA MaLis, Liat (2015). "La buena fe como mecanismo de integración eficiente", en Álvaro Vidal Olivares, Gonzalo Severin Fuster y Claudia Mejías Alonzo (eds.), Estudios de Derecho Civil X. Santiago: Thomson Reuters.

Teichmann, Arndt (1990). “Comentario § 242 BGB”, in Soergel. Bürgerliches Gesetzbuch mit Einführungsgesetz und Nebengesetzen. 12a ed. Stuttgart, Berlin, Köln: Verlag W. Kohlhammer.

Topitsch, Ernst (1972). "Sprachlogische Probleme der sozialwissenschaftlichen Theoriebildung", in Ernst TOPITSCH, (ed.), Logik der Sozialwissenschaften. $8^{\mathrm{a}}$ ed. Köln: Kiepenheuer \& Witsch.

WERNER, Fritz (1966). Zum Verhältnis von gesetzlichen Generalklauseln und Richterrecht. Karlsruhe: C. F. Müller.

Wieacker, Franz (1956). Zur rechtstheoretischen Präzisierung des § 242 BGB. Tübingen: J. C. B. Mohr (Paul Siebeck).

Wieacker, Franz (1967). Privatrechtsgeschichte der Neuzeit. $2^{\mathrm{a}}$ ed. Göttingen: Vandenhoeck \& Ruprecht.

Whittaker, Simon, Reinhard Zimmermann (2008). "Good faith in European contract law: surveying the legal landscape", in Simon WhitTaker, Reinhard Zimmermann (eds.), Good Faith in European Contract Law. Cambridge: University Press.

Zweigert, Konrad \& Hein KöTz, (1996). Einführung in die Rechtsvergleichung. $3^{\text {a }}$ ed. Tübingen: J. C. B. Mohr (Paul Siebeck).

Normas citadas

Código Civil de Chile.

Ley n. ${ }^{\circ}$ 19496, Normas sobre Protección de los Derechos de los Consumidores. Diario Oficial, 7 de marzo de 1997.

\section{Jurisprudencia citada}

Administradora de Recursos Humanos y Marketing en Línea Apedex Limitada con Distribución y Servicio D y S S.A., Corte Suprema, 27 de enero de 2012, rol n. ${ }^{\circ}$ 1180-2011 (casación en el fondo), Westlaw Chile CL/JUR/1965/2012

Castro Hidalgo Leonel con Araneda Campos Mauricio, Corte Suprema, 2 de junio de 2014, rol n. ${ }^{\circ}$ 4830-2013 (casación en el fondo), Westlaw Chile CL/ JUR/2805/2014.

Construcciones e Inversiones C. P. M. Limitada con Banco Santander Chile, Corte Suprema, 19 de octubre de 2010, rol n. ${ }^{\text {o }}$ 2236-2009 (casación en el fondo), Westlaw Chile CL/JUR/8562/2010

Frutícola El Aromo S.A. con María Consuelo Camposano Ibarra y otros, Corte de Apelaciones de Santiago, 10 de octubre de 2014, rol n. ${ }^{\circ}$ 579-2014 (apelación), Westlaw Chile CL/JUR/7305/2014 
Inmobiliaria Velamar S.A.C. con Teresa Godoy Muñoz, Corte Suprema, 4 de abril de 2018, rol n. ${ }^{\circ}$ 36338-2017 (casación en el fondo), Westlaw Chile CL/ JUR/1542/2018

Juan Salinas Sepúlveda con Servicio de Salud Atacama, Corte Suprema, 31 de

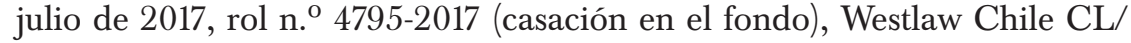
JUR/5047/2017

Luis Pérez Castro con Aguas Araucanía S.A., Corte Suprema, 3 de noviembre de 2011, rol n. ${ }^{\circ}$ 6734-2010 (casación en el fondo), Microjuris MJCH_MJJ29879

Luis Pérez Inostroza con Lucía Pérez Inostroza, Corte Suprema, 5 de abril de 2018, rol n. ${ }^{0}$ 16618-2017 (casación en el fondo), Westlaw Chile CL/JUR/1567/2018

Macarena Bustos Valdés con María Lombardi Aranda, Corte Suprema, 14 de noviembre de 2016, rol n. ${ }^{\circ}$ 5746-2016 (casación en el fondo), Westlaw Chile CL/JUR/7557/2016

Marcela Conejera Marchant con Jumbo Administradora S.A., Corte Suprema, 29 de julio de 2010, rol n. ${ }^{\circ}$ 1287-2010 (casación en el fondo), Microjuris MJCH_MJJ24457

Paola Flores Clunes y otros con Parque Arauco S.A., Corte de Apelaciones de Santiago, 17 de octubre de 2013, rol n. ${ }^{o}$ 3918-2013 (apelación), Westlaw Chile CL/JUR/7699/2014

Patricio Quezada Petersen con Gabriela Rivas Moraga, Corte Suprema, 25 de octubre de 2016, rol n. ${ }^{\circ}$ 24425-2016 (casación en el fondo), Westlaw Chile CL/JUR/7209/2016

Servicio Nacional del Consumidor con Inmobiliaria Las Encinas de Peñalolén S.A., Corte Suprema, 9 de noviembre de 2015, rol n. ${ }^{\circ}$ 23092-2014 (casación en el fondo), Westlaw Chile CL/JUR/6769/2015

Sociedad Constructora Miramar con Inversad Corza S.A., Corte Suprema, 8 de marzo de 2012, rol n. ${ }^{\circ} 4313-2011$ (casación en el fondo), Westlaw Chile CL/ JUR/532/2012

Transporte Travasa Limitada con HDI Seguros S.A., Corte Suprema, 21 de marzo de 2018, Rol Nr. 5100-2017 (casación en el fondo), Westlaw Chile CL/ JUR/1608/2018

Víctor Mena Lobos con Banco Santander, Corte Suprema, 31 de agosto de 2016, rol n. ${ }^{\mathrm{o}}$ 16323-2016 (casación en el fondo), Westlaw Chile CL/JUR/6107/2016

Wilibaldo Moreno Loyola con Banco Santander Chile, Corte Suprema, 26 de agosto de 2015, rol n. ${ }^{\circ}$ 26847-2014 (casación en el fondo), Westlaw Chile CL/JUR/4847/2015. 